\title{
Mitochondrial Nitric Oxide Mediates Decreased Vulnerability of Hippocampal Neurons from Immature Animals to NMDA
}

\author{
Jeremy D. Marks, ${ }^{1,2,3}$ Chan Boriboun, ${ }^{1}$ and Janice Wang ${ }^{1}$ \\ ${ }^{1}$ Department of Pediatrics and the Committees on ${ }^{2}$ Cell Physiology and ${ }^{3}$ Molecular Medicine, University of Chicago, Chicago, Illinois 60637
}

\begin{abstract}
Mitochondrial membrane potential $\left(\Delta \Psi_{\mathrm{m}}\right)$-dependent $\mathrm{Ca}^{2+}$ uptake plays a central role in neurodegeneration after NMDA receptor activation. NMDA-induced $\Delta \Psi_{\mathrm{m}}$ dissipation increases during postnatal development, coincident with increasing vulnerability to NMDA. NMDA receptor activation also produces nitric oxide (NO), which can inhibit mitochondrial respiration, dissipating $\Delta \Psi_{\mathrm{m}}$. Because $\Delta \Psi_{\mathrm{m}}$ dissipation reduces mitochondrial $\mathrm{Ca}^{2+}$ uptake, we hypothesized that NO mediates the NMDA-induced $\Delta \Psi_{\mathrm{m}}$ dissipation in immature neurons, underlying their decreased vulnerability to excitotoxicity. Using hippocampal neurons cultured from 5- and 19-d-old rats, we measured NMDA-induced changes in $\left[\mathrm{Ca}^{2+}\right]_{\text {cytosol }}, \Delta \Psi_{\mathrm{m}}, \mathrm{NO}$, and $\left[\mathrm{Ca}^{2+}\right]_{\text {mito. }}$. In postnatal day 5 (P5) neurons, NMDA mildly dissipated $\Delta \Psi_{\mathrm{m}}$ in a NO synthase (NOS)-dependent manner and increased NO. The NMDA-induced NO increase was abolished with carbonyl cyanide 4-(trifluoromethoxy)phenyl-hydrazone and regulated by $\left[\mathrm{Ca}^{2+}\right]_{\text {mito }}$. Mitochondrial $\mathrm{Ca}^{2+}$ uptake inhibition prevented the NO increase, whereas inhibition of mitochondrial $\mathrm{Ca}^{2+}$ extrusion increased it. Consistent with this mitochondrial regulation, NOS and cytochrome oxidase immunoreactivity demonstrated mitochondrial localization of NOS. Furthermore, NOS blockade increased mitochondrial $\mathrm{Ca}^{2+}$ uptake during NMDA. Finally, at physiologic $\mathrm{O}_{2}$ tensions $\left(3 \% \mathrm{O}_{2}\right)$, NMDA had little effect on survival of P5 neurons, but NOS blockade during NMDA markedly worsened survival, demonstrating marked neuroprotection by mitochondrial NO. In P19 neurons, NMDA dissipated $\Delta \Psi_{\mathrm{m}}$ in an NO-insensitive manner. NMDA-induced NO production was not regulated by $\Delta \Psi_{\mathrm{m}}$, and NOS immunoreactivity was cytosolic, without mitochondrial localization. NOS blockade also protected P19 neurons from NMDA. These data demonstrate that mitochondrial NOS mediates much of the decreased vulnerability to NMDA in immature hippocampal neurons and that cytosolic NOS contributes to NMDA toxicity in mature neurons.
\end{abstract}

Key words: NMDA; mitochondria; nitric oxide; calcium; development; mtNOS

\section{Introduction}

Mitochondria play important roles in neuronal death after activation of NMDA receptors, a central mechanism of hypoxicischemic brain injury (Rothman, 1984; Choi and Rothman, 1990; Beal, 1992). Excitotoxicity-induced mitochondrial dysfunction leads to energy failure (Lang-Rollin et al., 2003), neuronal necrosis (Gwag et al., 1997; Colbourne et al., 1999; Niquet et al., 2003), increased production of reactive oxygen species (Sengpiel et al., 1998; Castilho et al., 1999; Luetjens et al., 2000), and apoptosis (Ankarcrona et al., 1995; Wang et al., 2004).

Mitochondrial dysfunction during excitotoxicity depends on mitochondrial membrane potential $\left(\Delta \Psi_{\mathrm{m}}\right)$-driven uptake of $\mathrm{Ca}^{2+}$ into mitochondria, and excitotoxic neuronal death depends on this $\mathrm{Ca}^{2+}$ uptake (Dessi et al., 1995; Budd and Nicholls, 1996; Pivovarova et al., 2004). Preventing mitochondrial $\mathrm{Ca}^{2+}$ uptake by first dissipating $\Delta \Psi_{\mathrm{m}}$ blocks excitotoxic neuronal

Received 0ct. 2, 2003; revised May 27, 2005; accepted May 28, 2005.

This study was supported by National Institute of Neurological Disorders and Stroke Grant R01 NS38547. We thank Vytas Bindokas and Paul Schumacker for helpful discussions on this manuscript.

Correspondence should be addressed to Jeremy D. Marks, Department of Pediatrics, MC6060, University of Chicago, 5841 South Maryland Avenue, Chicago, IL 60637. E-mail: j-marks1@uchicago.edu.

DOI:10.1523/JNEUROSCI.1450-05.2005

Copyright $\odot 2005$ Society for Neuroscience $\quad 0270-6474 / 05 / 256561-15 \$ 15.00 / 0$ death, despite the large increases in cytosolic free calcium concentration $\left(\left[\mathrm{Ca}^{2+}\right]_{\text {cytosol }}\right)$ that accompany removal of this $\mathrm{Ca}^{2+}$ sink (Stout et al., 1998). Similarly, overexpression of mitochondrial uncoupling protein 2, which modestly dissipates $\Delta \Psi_{\mathrm{m}}$, reduces neuronal death from stroke and trauma (Mattiasson et al., 2003).

In hippocampal neurons, vulnerability to excitotoxic death changes markedly during postnatal development (Liu et al., 1996; Marks et al., 1996, 2000). Thus, despite similar NMDA-induced bulk $\left[\mathrm{Ca}^{2+}\right]_{\mathrm{i}}$ increases in immature and mature neurons, death of cultured hippocampal neurons prepared from newborn $(0-5$ $\mathrm{d}$ old) animals is minimal but increases sharply in neurons from increasingly older animals, becoming nearly universal in neurons from mature (19-25 d old) animals (Marks et al., 2000). During maturation, mitochondrial responses to NMDA also change dramatically: in neurons from newborns, NMDA induces mild, transient $\Delta \Psi_{\mathrm{m}}$ dissipation, whereas those from mature animals exhibit profound, long-lasting $\Delta \Psi_{\mathrm{m}}$ dissipation (Marks et al., 2000). The profound $\Delta \Psi_{\mathrm{m}}$ dissipation in mature neurons may reflect mitochondrial $\mathrm{Ca}^{2+}$ uptake, energy failure, and, under some conditions, mitochondrial permeability transition pore opening (Brustovetsky and Dubinsky, 2000; Maciel et al., 2001; Kobayashi et al., 2003). However, mechanisms underlying the 
mild, NMDA-induced $\Delta \Psi_{\mathrm{m}}$ dissipation in neurons from immature animals are unclear, as are its consequences.

Under some conditions, NMDA-induced $\Delta \Psi_{\mathrm{m}}$ dissipation is abolished by inhibition of nitric oxide (NO) synthase (NOS) (Almeida et al., 1999; Keelan et al., 1999). NO dissipates $\Delta \Psi_{\mathrm{m}}$ at nanomolar concentrations, reversibly competing with $\mathrm{O}_{2}$ for the reduced binuclear center $\mathrm{Cu}_{\mathrm{B}} / a_{3}$ of cytochrome oxidase (Brown, 1999; Antunes et al., 2004). This competition transiently inhibits oxidative phosphorylation, precluding maintenance of $\Delta \Psi_{\mathrm{m}}$ in the face of ongoing ATP synthesis. By dissipating $\Delta \Psi_{\mathrm{m}}$ during elevations of $\left[\mathrm{Ca}^{2+}\right]_{\text {cytosol }}$, $\mathrm{NO}$ may reduce mitochondrial $\mathrm{Ca}^{2+}$ uptake and subsequent cell death in neurons, a phenomenon reported in cardiomyocytes in vitro during ischemia-reperfusion injury (Rakhit et al., 2001).

Because NMDA induces mild $\Delta \Psi_{\mathrm{m}}$ dissipation in newborn hippocampal neurons with little subsequent death, we hypothesized that this $\Delta \Psi_{\mathrm{m}}$ dissipation results from NMDA-induced NO production and that this NO production protects neurons after NMDA. Accordingly, using cultures of hippocampal neurons from newborn and mature animals, we assessed the role played by NO production in mediating this developmentally regulated resistance to NMDA and ascertained the mechanisms underlying its regulation.

\section{Materials and Methods}

Culture media and supplements were obtained from Invitrogen (Carlsbad, CA). Fura-2, fura-FF, rhod-2, 3-amino-4-( $N$-methylamino $)-2^{\prime}, 7^{\prime}$ difluorofluorescein (DAF-FM), Mitofluor red, tetramethylrhodaminemethylester (TMRM), and Alexa 488-conjugated anti-cytochrome oxidase (subunit I) came from Molecular Probes (Eugene, OR). Ru-360 and $\mathrm{Mn}(\mathrm{III})$ tetrakis(4-benzoic acid)porphyrin (MnTBAP) were purchased from EMD Biosciences (San Diego, CA). 7-Chloro-5-(2chlorophenyl)-1,5-dihydro-4,1-benzothiazepin-2(3H)-one (CGP37157) and $1 H$-[1,2,4] oxadiazolo[4,3-a]quinoxalin-1-one (ODQ) were from Biomol (Plymouth Meeting, PA). Anti-neuronal nitric oxide synthase (nNOS) was obtained from BD Transduction Laboratories (Lexington, KY). All other chemicals were from Sigma (St. Louis, MO). For epifluorescence imaging, all filters and mirrors were obtained from Chroma Technology (Brattleboro, VT).

Postnatal hippocampal neurons. Hippocampal neurons were prepared from immature ( $5 \mathrm{~d}$ old $)$ and mature ( $19 \mathrm{~d}$ old) Sprague Dawley rats as described previously (Marks et al., 2000), with modifications. Briefly, isoflurane-anesthetized rats were decapitated, and the hippocampi were removed, sectioned $(400 \mu \mathrm{m})$, and incubated in oxygenated, $\mathrm{pH}$ buffered saline. Sections were incubated at room temperature with trypsin type XIII $(0.5-1.0 \mathrm{mg} / \mathrm{ml})$ for $30 \mathrm{~min}$, then with Pronase $(0.4 \mathrm{mg} / \mathrm{ml})$ for $15 \mathrm{~min}$, and mechanically triturated. Dissociated cells were centrifuged through an iodixanol density gradient $(1.055-1.026 \mathrm{~g} / \mathrm{ml})$ and plated onto poly-D-lysine-coated coverslips. Coverslips were placed on a layer of cultured cortical astrocytes, maintained in DMEM supplemented with HEPES ( $15 \mathrm{~mm}), \mathrm{N} 2$, and ovalbumin, and incubated in a humidified atmosphere containing $\mathrm{O}_{2}(5 \pm 0.1 \%)$ and $\mathrm{CO}_{2}(10 \pm 0.1 \%)$ at $35^{\circ} \mathrm{C}$. We have shown previously that these postnatal hippocampal neurons depend on a $5 \% \mathrm{O}_{2}$ atmosphere for survival in culture (Marks et al., 2000). Neurons were studied between 4 and $7 \mathrm{~d}$ in vitro.

Microscopy, imaging, and fluorescence quantification. Under xenon illumination, dye-loaded neurons were observed under epifluorescence using either a $40 \times, 1.3$ numerical aperture (NA) Plan Fluor objective or a $100 \times, 1.40$ NA Plan Apo objective in an inverted microscope (Nikon, Tokyo, Japan) and imaged with a cooled CCD camera (Photometrics, Tucson, AZ) connected to a computer workstation running Metafluor imaging software (Universal Imaging, Downington, PA). Multiple fluorophores were simultaneously used by means of polychroic mirrors, in conjunction with narrow bandpass filters in computer-controlled excitation and emission wheels. Images of a drop of dye-free perfusate were used for background correction. Non-uniform illumination in the imag- ing system was corrected by dividing each image by a fluorescence image of a homogenous, uranium oxide slide, and the resultant image was scaled. Background-subtracted, shading-corrected intracellular fluorescence measurements were made every $20 \mathrm{~s}$ before, during, and after perfusion of NMDA. For cytosolic dyes, mean somal fluorophorespecific fluorescence was calculated for each cell in the image, and fluorescence intensities were plotted on a region-by-region basis as a function of time.

Time-lapse studies. Coverslips were placed in a closed recording chamber (Warner Instrument, New Haven, CT) on the microscope stage and perfused (1-2 $\mathrm{ml} / \mathrm{min}$ ) with bicarbonate-buffered saline. The composition of the buffer (control buffer) was as follows (in mM): $125 \mathrm{NaCl}, 3.0$ $\mathrm{KCl}, 1.25 \mathrm{NaH}_{2} \mathrm{PO}_{4}, 1.3 \mathrm{Mg}_{2} \mathrm{SO}_{4}, 2.4 \mathrm{CaCl}_{2}, 10$ glucose, and $26 \mathrm{NaHCO}_{3}$. Unless otherwise stated, the perfusate was bubbled with $21 \% \mathrm{O}_{2} / 5 \%$ $\mathrm{CO}_{2}$. In experiments in which $\mathrm{pO}_{2}$ was manipulated, buffers were equilibrated before the experiment by bubbling with a mixture of $5 \% \mathrm{CO}_{2}$ and a calibrated $\mathrm{O}_{2}$ concentration. Perfusate $\mathrm{pO}_{2}$ was controlled using gasequilibrated solutions that were delivered to the glass-sealed chamber with flexible stainless steel tubing. Neurons were maintained at $34.5 \pm$ $0.2^{\circ} \mathrm{C}$.

Measurement of $\left[\mathrm{Ca}^{2+}\right]_{i}$. $\left[\mathrm{Ca}^{2+}\right]_{\mathrm{i}}$ was measured with either fura- $2\left(K_{\mathrm{d}}\right.$ of $224 \mathrm{nM}$ ) or fura-FF ( $K_{\mathrm{d}}$ of $\left.5.5 \mu \mathrm{M}\right)$, loaded as AM esters for $1 \mathrm{~h}$ at $35^{\circ} \mathrm{C}$. After loading, cultures were washed in $\mathrm{HCO}_{3}$-buffered saline for at least 15 min to ensure complete hydrolysis of the AM ester. Fura dyes were sequentially excited using $10 \mathrm{~nm}$ bands of light centered on 340 and 380 $\mathrm{nm}$, and a 40-nm wide band of fluorescence centered on $535 \mathrm{~nm}$ was imaged.

Measurement of changes in $\left[\mathrm{Ca}^{2+}\right]_{\text {mito }}$. Changes in mitochondrial matrix free calcium concentrations $\left[\mathrm{Ca}^{2+}\right]_{\text {mito }}$ were measured using the cationic fluorescent calcium indicator rhod-2. Rhod-2 was reduced with $\mathrm{NaBH}_{4}$ to the nonfluorescent dihydro-rhod-2 before loading. Neurons were incubated in dihydro-rhod-2 AM $(3 \mu \mathrm{M})$ for $1 \mathrm{~h}$ at room temperature in HEPES-buffered saline and then washed for $15 \mathrm{~min}$ in culture medium at $35^{\circ} \mathrm{C}$. Neurons were excited with a $20 \mathrm{~nm}$ band of light centered on $548 \mathrm{~nm}$, and a $40 \mathrm{~nm}$ wide band of fluorescence centered on 600 $\mathrm{nm}$ was imaged, using a $100 \times$ plan Apo objective. To decrease light emanating from outside the plane of focus, time-lapse images were deconvolved using software using maximum likelihood estimation (Huygens Essential; Scientific Volume Imaging, Hilversum, The Netherlands).

Measurement of cellular nitric oxide. Changes in intracellular NO concentration were monitored using DAF-FM, a non-fluorescent compound that is irreversibly nitrosated by an NO-dependent mechanism to a fluorescent triazole (Itoh et al., 2000). DAF-FM intensity also exhibits no $\mathrm{pH}$ dependence over the physiologic range (Kojima et al., 1999). Neurons were loaded with DAF-FM diacetate $(10 \mu \mathrm{M})$ for $1 \mathrm{~h}$ at $35^{\circ} \mathrm{C}$ in culture media, and the coverslips washed in bicarbonate-buffered saline, $\mathrm{pH} 7.4$, for $15 \mathrm{~min}$ at $35^{\circ} \mathrm{C}$. Neurons were excited with a $10 \mathrm{~nm}$ wide band of light centered on $480 \mathrm{~nm}$, and a $40 \mathrm{~nm}$ wide band of fluorescence centered on $535 \mathrm{~nm}$ was imaged. Polychroic beam splitters were used to allow simultaneous imaging of fura-2 and DAF-FM and of DAF-FM and Mitofluor red 589. Mean somal DAF-FM intensity was calculated for each neuron in the microscopic field. Time-dependent changes in somal DAF-FM intensity were expressed as percentage change from baseline $(\Delta F / F)$. Linear regression was used to quantify the rate of triazole fluorescence rise before and during NMDA. The rate of rise during the 2-3 min immediately before NMDA was used to calculate the baseline slope. Because the rate of rise after NMDA tapered off after 5-7 min, the initial 4 min after the onset of the NMDA-induced $\left[\mathrm{Ca}^{2+}\right]_{\mathrm{i}}$ rise was used to calculate the NMDA response. Statistical tests for repeated measures were used to assess differences between slopes in neurons obtained at baseline and during NMDA.

Measurement of $\Delta \Psi_{m}$. To assess changes in $\Delta \Psi_{\mathrm{m}}$, we used TMRM, a cationic fluorophore that is concentrated within polarized mitochondria as a function of potential. We ensured that neurons were exposed to a constant concentration of TMRM throughout the experiment by diluting TMRM into bicarbonate-buffered saline solution to a concentration of $0.5 \mathrm{~nm}$ and then deriving all solutions used in the experiment from this stock. Neurons were incubated at $35^{\circ} \mathrm{C}$ for $1 \mathrm{~h}$ in TMRM-containing saline to allow electrochemical equilibration of TMRM across the plasma 
and inner mitochondrial membranes. This low concentration ensured that intramitochondrial TMRM was not quenched at baseline (polarized) mitochondrial potentials. In this way, graded $\Delta \Psi_{\mathrm{m}}$ dissipation was evidenced by graded loss of TMRM fluorescence. TMRM-loaded neurons were excited with a $30 \mathrm{~nm}$ wide band of light centered on $560 \mathrm{~nm}$, attenuated by neutral density filters to $0.003 \%$ of unfiltered intensity, and a $55 \mathrm{~nm}$ wide band of fluorescence centered on $605 \mathrm{~nm}$ was imaged. The low illumination level enabled time-lapse studies to be performed for up to $1 \mathrm{~h}$ without light-induced dissipation of $\Delta \Psi_{\mathrm{m}}$. We used polychroic beam splitters to allow simultaneous use of fura-2 and TMRM.

TMRM fluorescence intensities were measured over time from mitochondria-rich and -poor regions of individual neurons. To eliminate contributions to changes in mitochondrial TMRM intensity made by plasma membrane depolarization, we divided the TMRM intensity of the mitochondria-rich region by that of the mitochondria-poor region of the neuron. Corrected fluorescence ratios were then normalized to baseline ratio $(100 \%)$ and the ratio obtained after dissipation of $\Delta \Psi_{\mathrm{m}}$ with carbonyl cyanide 4-(trifluoromethoxy)phenyl-hydrazone (FCCP) (0\%) and plotted as a function of time.

Manipulation of mitochondrial $\left[\mathrm{Ca}^{2+}\right]$. Mitochondrial $\mathrm{Ca}^{2+}$ uptake was blocked with $\mathrm{Ru}-360$, a cell-permeable oxygen-bridged dinuclear ruthenium amine complex that avidly $\left(\mathrm{IC}_{50}\right.$ of $\left.184 \mathrm{pm}\right)$ and specifically blocks $\mathrm{Ca}^{2+}$ uptake into mitochondria in vitro (Matlib et al., 1998). $\mathrm{Ru}-360$ was dissolved in $\mathrm{N}_{2}$-sparged water immediately before use. Neurons were incubated in $\mathrm{Ru}-360(10 \mu \mathrm{M})$ for $1 \mathrm{~h}$ before study. Mitochondrial $\mathrm{Ca}^{2+}$ efflux was blocked with CGP-37157, a specific blocker of the mitochondrial $\mathrm{Na}^{+} / \mathrm{Ca}^{2+}$ exchanger. This compound has some blocking activity at plasma membrane $\mathrm{Ca}^{2+}$ channels at the concentrations needed to block mitochondrial $\mathrm{Ca}^{2+}$ efflux (Baron and Thayer, 1997). To prevent CGP-37157 from reducing $\mathrm{Ca}^{2+}$ entry across the plasma membrane, we applied CGP-37157 according to published methods (White and Reynolds, 1997; Wang and Thayer, 2002): first perfusing neurons with NMDA briefly $(1 \mathrm{~min})$ and then switching the perfusate to one containing NMDA and CGP-37157 (10 $\mu \mathrm{M})$. In preliminary experiments, we found that the magnitude and time course of the initial $\left[\mathrm{Ca}^{2+}\right]_{\mathrm{i}}$ rise after the onset of NMDA stimulation was not different from untreated neurons.

Immunohistochemistry. Neurons were fixed in paraformaldehyde (4\% for $5 \mathrm{~min}$ ) and then washed three times in $0.1 \%$ Triton X-100. Antigen retrieval was performed by incubating coverslips in $50 \mathrm{~mm}$ Tris-buffered saline, $\mathrm{pH} 7.5$, at $95^{\circ} \mathrm{C}$ for $20 \mathrm{~min}$, followed by three washes in PBS. Nonspecific immunoreactivity was blocked with $10 \%$ goat serum. Cultures were incubated overnight at $4^{\circ} \mathrm{C}$ in $\mathrm{PBS}$ containing a polyclonal antibody generated against a C-terminal synthetic peptide sequence corresponding to amino acids 1095-1289 of human nNOS (1:500 dilution) and a monoclonal antibody to subunit I of human cytochrome oxidase, conjugated to the fluorescent molecule Alexa 488 (1:500 dilution). Immunoreactivity to nNOS was amplified and detected using an Alexa 594 conjugate of a goat anti-rabbit IgG antibody. Cytochrome oxidase and nNOS immunoreactivity were imaged using a $60 \times, 1.4$ NA objective, and optical slices through the cultures were obtained using the 488 and 543 $\mathrm{nm}$ lines, respectively, of an Olympus Optical (Tokyo, Japan) Fluoview 200 laser scanning confocal microscope.

Induction and assessment of neuronal death. Cultures were incubated for $20 \mathrm{~min}$ in a sterile manner to $\mathrm{Mg}^{2+}$-free, bicarbonate-buffered saline containing NMDA $(300 \mu \mathrm{M})$ and glycine $(5 \mu \mathrm{M})$ at $35^{\circ} \mathrm{C}$ in a $5 \% \mathrm{CO}_{2}$ atmosphere. Control cultures were incubated in saline without NMDA. To perform these experiments at ambient oxygen tensions, neurons were placed in a standard $5 \% \mathrm{CO}_{2}$ incubator for the duration of the exposure. To perform these experiments at $3 \% \mathrm{O}_{2} / 5 \% \mathrm{CO}_{2}$, neurons were placed into a hypoxic work station, consisting of a glove box and an attached airlock, in which $\mathrm{O}_{2}$ and $\mathrm{CO}_{2}$ levels were continuously regulated to within $\pm 0.1 \%$ (Coy Laboratory Products, Grass Lake, MI). Petrie dishes containing saline solutions were placed into the work station for $18 \mathrm{~h}$ before the experiment to ensure equilibration of oxygen tensions with the $3 \%$ environment. After exposure in either 21 or $3 \% \mathrm{O}_{2}$, cultures were placed into their original media and put back into their standard incubator. Neuronal death was assessed $48 \mathrm{~h}$ later by means of calcein AM ( 1 $\mu \mathrm{M})$ and propidium iodide $(1 \mu \mathrm{M})$ fluorescence to identify living (green) and dead (red) neurons, respectively. Cells were illuminated with $480 \mathrm{~nm}$ light, and the resultant red and green fluorescence was observed using a polychroic beam splitter and narrow emission filters. Living and dead neurons were counted in 36 adjacent high-power fields in a $6 \times 6$ grid in each coverslip. A minimum of six coverslips per age was counted, and the percentages of survival were averaged and normalized to control survival. Statistical analysis of differences between treatments was performed with ANOVA.

\section{Results}

\section{$\Delta \Psi_{\mathrm{m}}$ dissipation accompanies the rise in $\left[\mathrm{Ca}^{2+}\right]_{\mathrm{i}}$}

We first assessed the extent to which NMDA receptor activation dissipates $\Delta \Psi_{\mathrm{m}}$ in hippocampal neurons cultured from postnatal day 5 (P5) rats and the temporal relationship of the $\Delta \Psi_{\mathrm{m}}$ dissipation to the NMDA-induced $\left[\mathrm{Ca}^{2+}\right]_{\mathrm{i}}$ increase. We used fura-2 to identify the onset and offset of the NMDA-induced $\left[\mathrm{Ca}^{2+}\right]_{i}$ rise. Before NMDA stimulation, baseline $\left[\mathrm{Ca}^{2+}\right]_{\mathrm{i}}$ and corrected mitochondrial TMRM intensities were stable. After the onset of NMDA $(300 \mu \mathrm{M}),\left[\mathrm{Ca}^{2+}\right]_{\mathrm{i}}$ abruptly increased, remained elevated for the remainder of the $5 \mathrm{~min}$ NMDA stimulation, and then decreased monotonically after NMDA washout (Fig. 1A). NMDA transiently dissipated $\Delta \Psi_{\mathrm{m}}$, coinciding with, or immediately after (within one time-lapse imaging interval), the onset of the NMDA-induced $\left[\mathrm{Ca}^{2+}\right]_{\mathrm{i}}$ rise. The mean peak corrected TMRM intensity change from baseline $(-24.1 \pm 5.4 \%$ SEM; $n=$ 32 ) occurred 1-2 min into the NMDA stimulus. After NMDA removal, $\Delta \Psi_{\mathrm{m}}$ returned to baseline over $\sim 15$ min. NMDAinduced $\Delta \Psi_{\mathrm{m}}$ dissipation and recovery was observed in every neuron tested ( $n=32$ neurons on 8 coverslips).

\section{NOS activity is required for $\Delta \boldsymbol{\Psi}_{\mathrm{m}}$ dissipation}

Dissipation of $\Delta \Psi_{\mathrm{m}}$ after glutamate receptor excitotoxicity has been linked to NO production in embryonic hippocampal neuron cultures (Almeida et al., 1999; Keelan et al., 1999). To assess the role played by NO in P5 neurons, we measured NMDAinduced $\Delta \Psi_{\mathrm{m}}$ dissipation in neurons in which NOS activity had been blocked by pretreatment with $N_{\omega}$-nitro-L-arginine methyl ester (L-NAME) (100 $\mu \mathrm{M}$ for $3 \mathrm{~h})$. Pretreatment with L-NAME completely abolished the neuronal $\Delta \Psi_{\mathrm{m}}$ dissipation induced by NMDA $(-0.13 \pm 4.6 \%$ SEM; $n=11 ; p<0.01)$ (Fig. $1 B)$, suggesting that NOS activity is required for NMDA-induced $\Delta \Psi_{\mathrm{m}}$ dissipation in these P5 neurons.

Because the L-NAME-induced antagonism of $\Delta \Psi_{\mathrm{m}}$ dissipation may have been attributable to smaller $\mathrm{Ca}^{2+}$ rises after NMDA, we compared NMDA-induced $\left[\mathrm{Ca}^{2+}\right]_{i}$ rises in L-NAME-incubated neurons with unexposed neurons. However, high-affinity $\mathrm{Ca}^{2+}$ reporters, such as fura-2 $\left(K_{\mathrm{d}}\right.$ of $\left.224 \mathrm{nM}\right)$, differentiate poorly between toxic and nontoxic $\left[\mathrm{Ca}^{2+}\right]_{\mathrm{i}}$ levels that are attained during excitotoxic stimulation (Stout and Reynolds, 1999). Consequently, we used the low-affinity $\mathrm{Ca}^{2+}$ reporter fura-FF $\left(K_{\mathrm{d}}\right.$ of $\left.5.5 \mu \mathrm{M}\right)$. At baseline, fura-FF ratios did not differ significantly between control and L-NAME-treated neurons (control, $0.39 \pm 0.05$ vs L-NAME, $0.33 \pm 0.04$ arbitrary units, mean \pm SEM; $n=20$ ). Most importantly, the fura-FF ratio increase induced by NMDA $(300 \mu \mathrm{M})$ did not differ significantly between control and L-NAME-treated neurons (control, $1.23 \pm$ 0.28 vs L-NAME, $1.72 \pm 0.34$ arbitrary units, mean \pm SEM; $n=$ $20 ; p=0.4)$. Accordingly, the marked decrease in $\Delta \Psi_{\mathrm{m}}$ dissipation that we observed in the presence of L-NAME was not attributable to an L-NAME-associated decrease in bulk $\left[\mathrm{Ca}^{2+}\right]_{\mathrm{i}}$. Instead, blockade of $\Delta \Psi_{\mathrm{m}}$ dissipation by L-NAME suggested that NO production underlies NMDA-induced $\Delta \Psi_{\mathrm{m}}$ dissipation in these neurons.

To obtain additional evidence that NO production is the pri- 

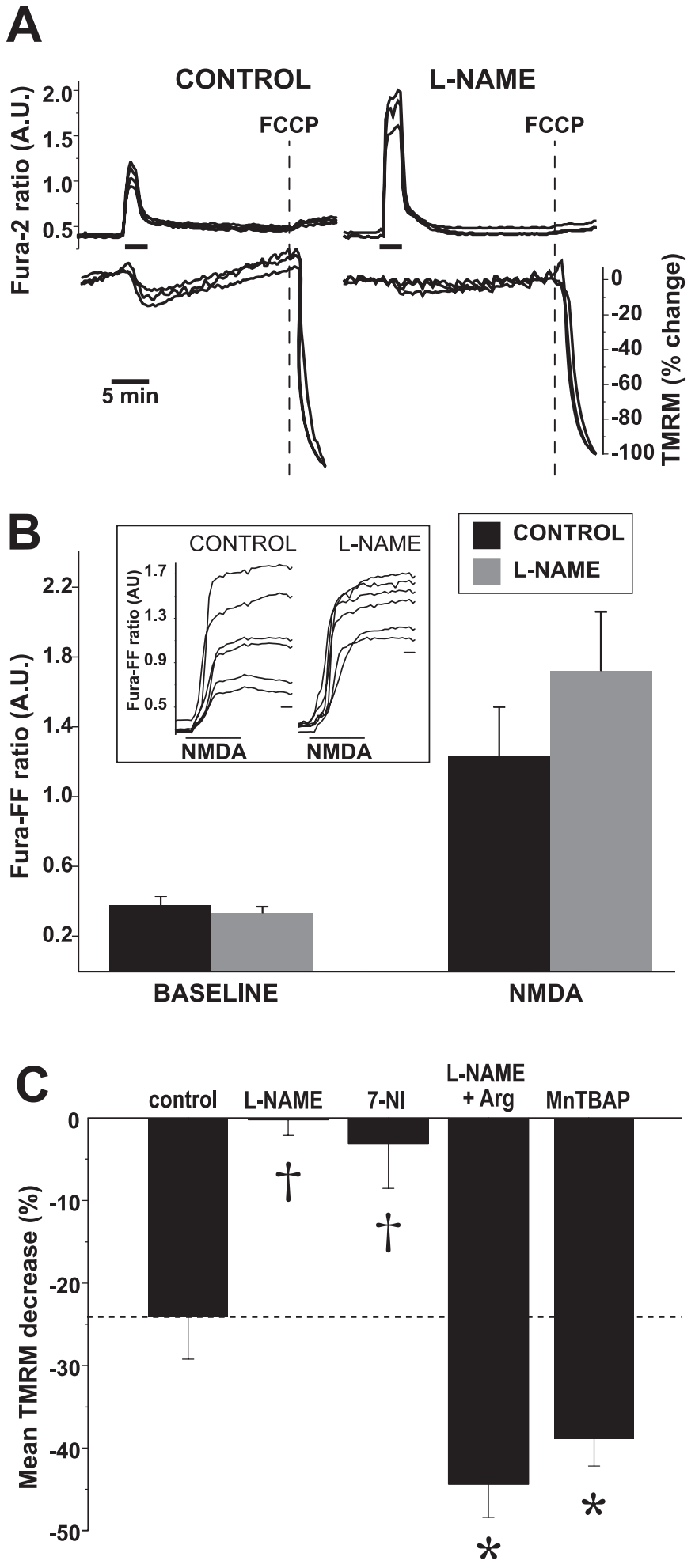

Figure 1. Inhibition of NOS prevents NMDA-induced $\Delta \Psi_{\mathrm{m}}$ dissipation. $A$, Simultaneous measures over time of NMDA-induced changes in $\left[\mathrm{Ca}^{2+}\right]_{\mathrm{i}}$ (fura-2) and $\Delta \Psi_{\mathrm{m}}$ (TMRM) in the absence (left) and presence (right) of L-NAME (100 $\mu \mathrm{m}$ for $3 \mathrm{~h}$ ). Maximal $\Delta \Psi_{\mathrm{m}}$ dissipation is induced with FCCP (dotted line) at the end of each experiment. To eliminate contributions to changes in mitochondrial TMRM intensity made by plasma membrane depolarization, TMRM intensities from a mitochondria-rich region of each neuron at each point in time was divided by the corresponding intensity from a mitochondria-poor region within the same neuron. Each ratio was normalized to the mean baseline ratio (100\%) and the mean ratio obtained after FCCP (0\%). NMDA induces a modest $\Delta \Psi_{\mathrm{m}}$ dissipation that is blocked by L-NAME. $\boldsymbol{B}$, Population summary of mean peak $\left[\mathrm{Ca}^{2+}\right]_{i}$ increases during NMDA in the presence and absence of NOS blockade. $\left[\mathrm{Ca}^{2+}\right]_{\mathrm{i}}$ increases are reported with fura-FF $\left(K_{\mathrm{d}}\right.$ of $\left.5.5 \mu \mathrm{m}\right)$. NMDA-induced $\left[\mathrm{Ca}^{2+}\right]_{\mathrm{i}}$ increases do not significantly differ between control and L-NAME. Inset, Representative exam- mary mechanism of NMDA-induced $\Delta \Psi_{\mathrm{m}}$ dissipation in these P5 neurons, we measured $\Delta \Psi_{\mathrm{m}}$ during NMDA in the presence of other compounds known to alter NO production (Fig. 1C). We first pretreated cultures with 7-nitroindazole (7-NI) $(100 \mu \mathrm{M}$ for $3 \mathrm{~h}$ ), a neuronal NOS-selective antagonist structurally unrelated to L-NAME (Babbedge et al., 1993). Similar to L-NAME, we found that 7-NI blocked NMDA-induced $\Delta \Psi_{\mathrm{m}}$ dissipation $(3.1 \pm 5.3 \% ; n=15 ; p<0.01)$. We also incubated L-NAME- and 7-NI-treated neurons in a 10-fold molar excess of arginine (1 $\mathrm{mm}$ ) to overcome the NOS blockade. Not only did arginine supplementation prevent the L-NAME-induced block of $\Delta \Psi_{\mathrm{m}}$ dissipation, arginine significantly increased the degree of NMDAinduced $\Delta \Psi_{\mathrm{m}}$ dissipation compared with control (44.4 $\pm 4.9 \%$; $n=27 ; p<0.05)$. Similar results were seen with argininesupplemented neurons incubated in 7-NI.

$\mathrm{NO}$ reacts at diffusion-limited rates with superoxide anion $\left(\mathrm{O}_{2}{ }^{\circ}\right)$ to form peroxynitrite (Huie and Padmaja, 1993). Consequently, $\mathrm{O}_{2} \cdot$ production, known to increase during NMDA (Lafon-Cazal et al., 1993; Bindokas et al., 1996), may, through peroxynitrite formation, reduce NO availability (Fennell et al., 2002). To assess whether peroxynitrite formation during NMDA reduces $\mathrm{NO}$ availability, we treated $\mathrm{P} 5$ neurons with MnTBAP, a superoxide dismutase mimetic, and measured NMDA-induced $\Delta \Psi_{\mathrm{m}}$ dissipation. Baseline TMRM ratios were not significantly different in MnTBAP-treated neurons compared with untreated neurons. However, NMDA induced a significantly larger $\Delta \Psi_{\mathrm{m}}$ dissipation in MnTBAP-treated neurons compared with untreated neurons (Fig. 1C), suggesting that a portion of the NO generated by NMDA in these neurons is converted to peroxynitrite, decreasing the NO effect on $\Delta \Psi_{\mathrm{m}}$. Together, these data strongly support the hypothesis that NMDA-induced $\Delta \Psi_{\mathrm{m}}$ dissipation in $\mathrm{P} 5$ neurons is attributable to NOS activation and $\mathrm{NO}$ production.

\section{NO production increases during NMDA receptor activation} in $\mathrm{P} 5$ neurons

To characterize the temporal relationship between NO production and $\Delta \Psi_{\mathrm{m}}$ dissipation in $\mathrm{P5}$ neurons, we next measured cellular NO production before and during NMDA. Because $\Delta \Psi_{\mathrm{m}}$ dissipates immediately after the onset of the NMDA-induced $\left[\mathrm{Ca}^{2+}\right]_{\mathrm{i}}$ increase, we used the onset of this $\left[\mathrm{Ca}^{2+}\right]_{\mathrm{i}}$ increase as a proxy for the onset of $\Delta \Psi_{\mathrm{m}}$ dissipation. To estimate NMDAinduced changes in NO production, we simultaneously measured time-dependent changes in fura-2 and DAF-FM fluorescence, a $\mathrm{pH}$-independent, NO-specific indicator (Itoh et al., 2000; Kojima et al., 2001). We used linear regression to quantify the slope of the DAF-FM fluorescence increase before and during the first 4 min of NMDA stimulation, beginning with the onset of the $\left[\mathrm{Ca}^{2+}\right]_{\mathrm{i}}$ rise. To confirm that the low intensity of UV and visible light excitation used in these fura-2/DAF-FM experiments did not induce noticeable DAF-FM nitrosation, we first performed control time-lapse experiments, measuring changes in DAF-FM intensity every $20 \mathrm{~s}$ in the absence of NMDA. Each DAF-FM exposure was preceded by acquisition of fura- 2 images at 340 and $380 \mathrm{~nm}$ excitation. We observed no significant changes

\footnotetext{
ples of raw fura-FF responses to NMDA in control and L-NAME-treated neurons. Calibration bar, 1 min. C, NMDA-induced $\Delta \Psi_{\mathrm{m}}$ dissipation is decreased during NOS blockade (L-NAME, 7-NI), and the blockade is overcome with supplemental $\mathrm{L}$-arginine (Arg). MnTBAP, a superoxide dismutase mimetic, increases NMDA-induced $\Delta \Psi_{m}$ dissipation, suggesting that a portion of the N0 generated by NMDA is converted to peroxynitrite. Statistical comparisons made between control and each treatment. ${ }^{*} p<0.05 ;{ }^{\dagger} p<0.01$. A.U., Arbitrary units.
} 


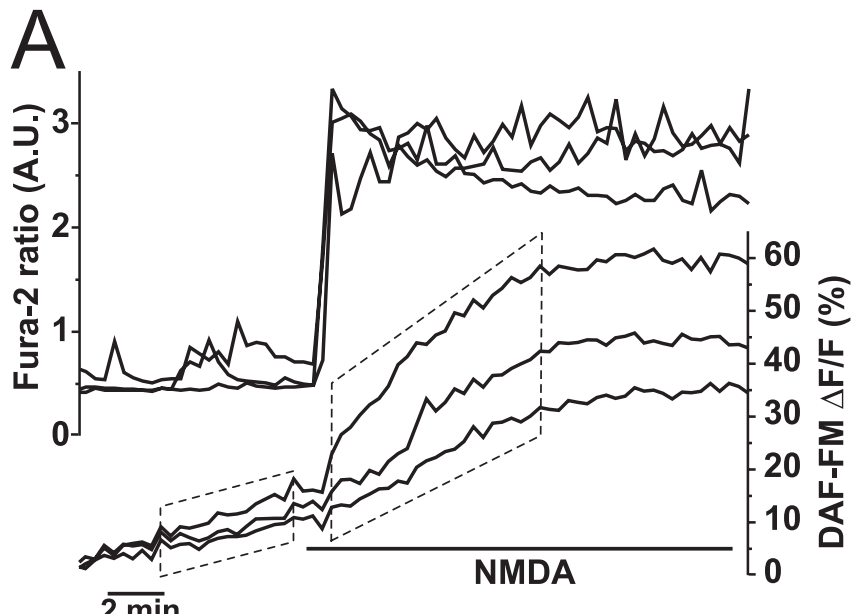

$\min$
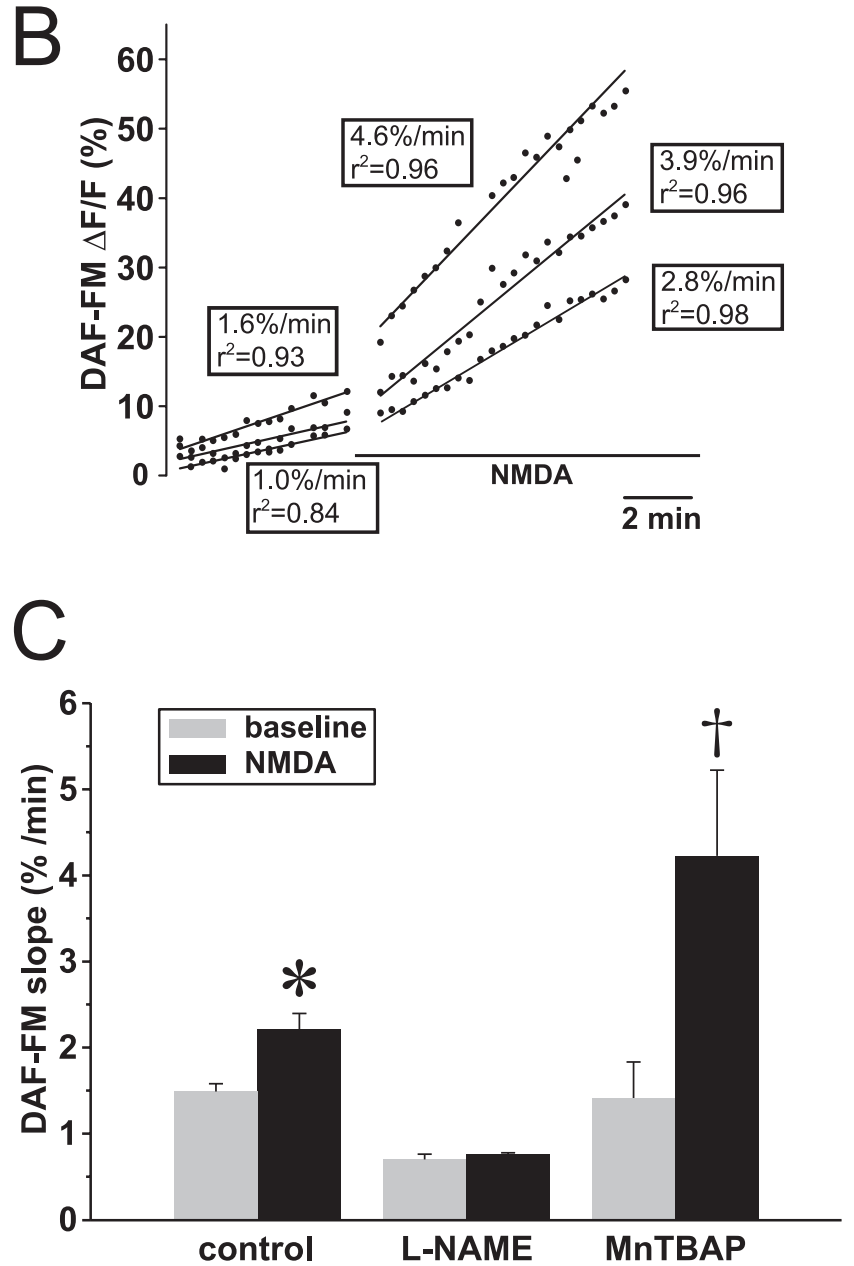

Figure 2. NMDA increases NO production in postnatal hippocampal neurons. A, Simultaneously obtained measures (every $20 \mathrm{~s}$ ) of changes in $\left[\mathrm{Ca}^{2+}\right]_{\mathrm{i}}$ (fura-2) and NO (DAF-FM) in response to NMDA (bar). The slope of DAF-FM fluorescence begins to increase coincident with the upstroke of the $\left[\mathrm{Ca}^{2+}\right]_{\mathrm{i}}$ rise. The boxes around the DAF-FM traces identify the regions used to calculate DAF-FM slopes at baseline and during the initial response to NMDA. $B$, Calculation of DAF-FM slopes. Data comprising the DAF-FM traces within the boxes in $\boldsymbol{A}$ are presented, and lines produced by linear regression of each trace are superimposed on each trace. Beside each line is presented the calculated DAF-FM slope and the correlation coefficient $\left(r^{2}\right)$ of each regression. Because of crowding, the calculated slope and $r^{2}$ for the middle baseline trace has been omitted. C, NMDA-induced increases in DAF-FM slope are prevented by NOS inhibition with L-NAME and increased with MnTBAP, a superoxide dismutase mimetic. Mean \pm SEM DAF-FM in DAF-FM slope from baseline over $30 \mathrm{~min}$, the length of a typical experiment $(n=18)$. Accordingly, under our experimental conditions, the increases in DAF-FM fluorescence we report are not the result of illumination.

During NMDA, the rate of rise of DAF-FM fluorescence increased markedly over the baseline slope in 17 of 21 neurons initially studied. This increase occurred immediately on the onset of the $\left[\mathrm{Ca}^{2+}\right]_{\mathrm{i}}$ rise (Fig. 2, top). The mean DAF-FM slope during NMDA was significantly greater compared with the mean baseline slope ( $n=34$ slopes in 17 neurons; $p<0.01$ by $t$ test for repeated measures) (Fig. 2, bottom). To confirm that these DAF-FM fluorescence increases reflect increased NO, we used pharmacological agents to alter NMDA-induced NO production (Fig. 2, bottom). Thus, L-NAME pretreatment (100 $\mu \mathrm{M}$ for $3 \mathrm{~h}$ ) decreased the DAF-FM slope at baseline and completely blocked the NMDA-induced slope increase $(n=20 ; p<0.01)$. Similar results were obtained with 7 -NI pretreatment. Finally, because we had observed that MnTBAP increased the magnitude of NMDA-induced $\Delta \Psi_{\mathrm{m}}$ dissipation, consistent with the reduction of $\mathrm{NO}$ availability through its interaction with $\mathrm{O}_{2}{ }^{\cdot}$ to form peroxynitrite, we assessed whether MnTBAP pretreatment increased the NMDA-induced DAF-FM slope increase. No significant differences were observed at baseline in MnTBAP-pretreated neurons. However, NMDA induced significantly larger DAF-FM slope increases compared with untreated neurons $(n=25)$. These findings demonstrate that NMDA increases NO production in P5 hippocampal neurons during the initial $\left[\mathrm{Ca}^{2+}\right]_{\mathrm{i}}$ rise, consistent with our finding of NOS-mediated $\Delta \Psi_{\mathrm{m}}$ dissipation during the same period, and suggest that a portion of this NO production is converted to peroxynitrite.

To assess whether the DAF-FM rise depended on the $\left[\mathrm{Ca}^{2+}\right]$ rise induced by NMDA, we measured DAF-FM and fura-2 responses to NMDA in the absence of extracellular $\mathrm{Ca}^{2+}$, using an otherwise identical perfusate containing EGTA ( $5 \mathrm{~mm}$ ) and no added $\mathrm{Ca}^{2+}$. Removal of extracellular $\mathrm{Ca}^{2+}$ completely blocked both the NMDA-induced $\left[\mathrm{Ca}^{2+}\right]_{i}$ rise and the increase in DAF-FM slope during NMDA $(n=41)$, demonstrating its dependence on the NMDA-induced $\left[\mathrm{Ca}^{2+}\right]_{\mathrm{i}}$ increase. Thus, this $\mathrm{Ca}^{2+}$-dependent increase in NO that occurs during NMDA receptor activation likely mediates the NOS-dependent $\Delta \Psi_{\mathrm{m}}$ dissipation that occurs during NMDA.

Increased NO production and $\Delta \Psi_{\mathrm{m}}$ dissipation are specific to NMDA receptor activation

We next asked whether the $\Delta \Psi_{\mathrm{m}}$ dissipation and increased NO production that we observed after NMDA also occurred after $\left[\mathrm{Ca}^{2+}\right]_{\mathrm{i}}$ increases that were not mediated by NMDA. We induced a $\left[\mathrm{Ca}^{2+}\right]_{\mathrm{i}}$ rise through activation of plasma membrane voltagegated $\mathrm{Ca}^{2+}$ channels, by depolarizing neurons with an otherwise identical, bicarbonate-buffered saline solution, in which $60 \mathrm{~mm}$ $\mathrm{NaCl}$ had been replaced with $\mathrm{KCl}$. During 5 min exposures to high $\mathrm{K}^{+}$solution, the somal fura-2 ratio significantly increased (mean \pm SEM ratios, baseline, $0.5 \pm 0.06$ vs depolarizing solution, $1.05 \pm 0.05$ arbitrary units; $n=23 ; p<0.01$ ) (Fig. 3, left inset). In contrast, the slope of DAF-FM fluorescence did not

slopes at baseline and during the initial 4 min of NMDA stimulation obtained by linear regression in untreated neurons and neurons in which N0 production has been blocked (L-NAME) or increased (MnTBAP). MnTBAP, by removing $\mathrm{O}_{2}{ }^{\circ}$, prevents $\mathrm{NO}$ consumption by decreasing peroxynitrite formation, increasing $\mathrm{NO}$ availability. Statistical comparisons are made within treatments, comparing the DAF-FM slope during NMDA with that slope during baseline. ${ }^{*} p<0.05$; ${ }^{\dagger} p<0.01$. A.U., Arbitrary units. 

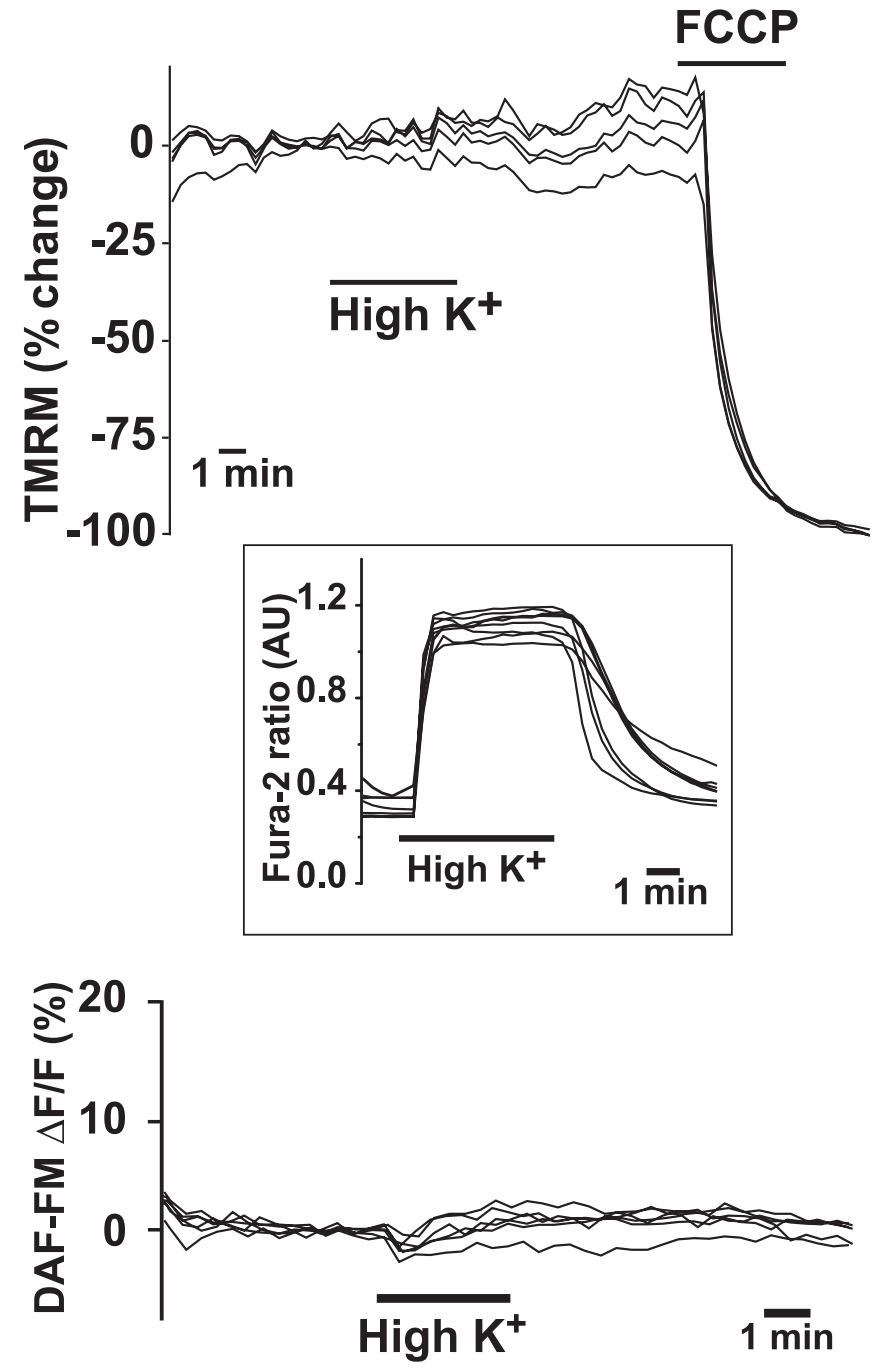

Figure 3. Voltage-gated $\mathrm{Ca}^{2+}$ channel activation by plasma membrane depolarization with $60 \mathrm{~mm} \mathrm{KCL}\left(\right.$ High $\mathrm{K}^{+}$) neither dissipates $\Delta \Psi_{\mathrm{m}}$ (top) nor increases NO production (bottom). FCCP administration demonstrates maximal $\Delta \Psi_{\mathrm{m}}$ dissipation. Inset shows typical depolarization-induced $\left[\mathrm{Ca}^{2+}\right]_{\mathrm{i}}$ elevation, as reported by fura- 2 .

change significantly (slope increase, $0.52 \pm 0.42 \% / \mathrm{min}$, mean \pm SEM; $n=23 ; p=0.23$ ) (Fig. 3, left bottom). Furthermore, in separate experiments using TMRM, we observed no $\Delta \Psi_{\mathrm{m}}$ dissipation during exposure to depolarizing solutions (mean \pm SEM loss of TMRM fluorescence, baseline, $-2.7 \pm 0.8 \%$ vs depolarization, $-4.6 \pm 1.5 \% ; n=19$ ) (Fig. 3, left top). The lack of $\Delta \Psi_{\mathrm{m}}$ dissipation during plasma membrane depolarization also provides additional evidence that the change in TMRM fluorescence observed during NMDA does not represent an artifact of plasma membrane depolarization but rather $\Delta \Psi_{\mathrm{m}}$ dissipation.

NMDA dissipates $\Delta \boldsymbol{\Psi}_{\mathrm{m}}$ as a function of $\mathrm{O}_{2}$ concentration Having found an NO increase temporally associated with NMDA-induced $\Delta \Psi_{\mathrm{m}}$ dissipation, we next sought to characterize the mechanisms by which NO dissipates $\Delta \Psi_{\mathrm{m}}$ in this context. We first assessed whether $\Delta \Psi_{\mathrm{m}}$ dissipation depended on NOmediated activation of soluble guanylate cyclase, by treating neurons, before NMDA, with the guanylate cyclase inhibitor ODQ (10 $\mu \mathrm{M}$ for $30 \mathrm{~min}$ ). ODQ-treated neurons demonstrated the identical degree of NMDA-induced TMRM decrease compared with untreated neurons (ODQ, $29.1 \pm 4.5 \%$ vs control, $29.4 \pm$

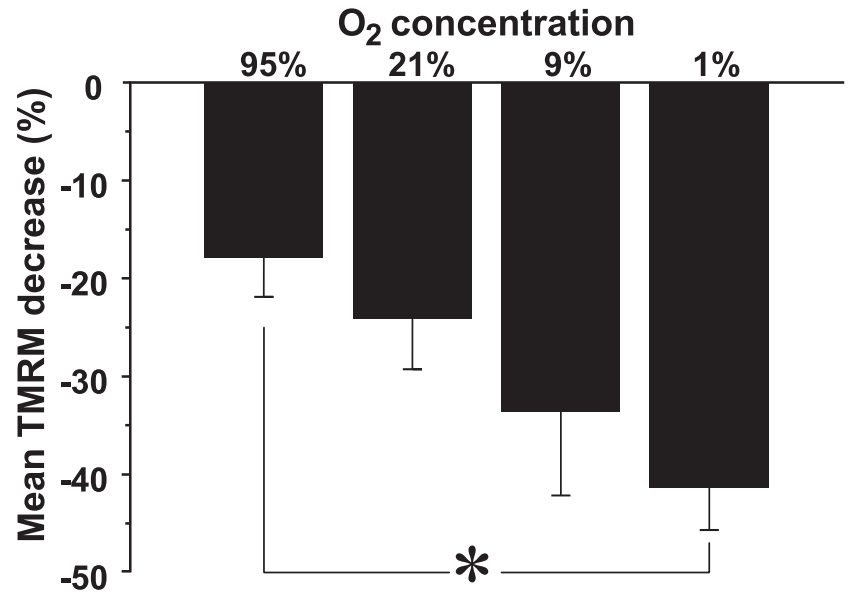

Figure 4. NMDA increasingly dissipates $\Delta \Psi_{\mathrm{m}}$ at progressively lower $\mathrm{O}_{2}$ concentrations. Before NMDA, cultures were equilibrated in one of four $\mathrm{O}_{2}$ concentrations, during which time TMRM changes were measured every $20 \mathrm{~s}$. No changes in baseline TMRM fluorescence intensity ratios occurred at any $\mathrm{O}_{2}$ concentration used. Progressively greater mean peak $\Delta \Psi_{\mathrm{m}}$ dissipation was observed as $\mathrm{O}_{2}$ concentration decreased. ${ }^{*} p<0.05$.

$5.1 \% ; n=66 ; p=0.95)$, indicating that guanylate cyclase activation plays no role in NO-mediated $\Delta \Psi_{\mathrm{m}}$ dissipation.

A more likely, well described mechanism (Brown, 2001) is the binding of $\mathrm{NO}$ to the binuclear $\mathrm{Cu}_{\mathrm{B}} /$ cytochrome $a_{3}$ site of cytochrome $c$ oxidase (E.C. 1.9.3.1) (Webb, 1992), the terminal complex of the mitochondrial respiratory chain. Because NO binding to cytochrome $c$ is competitive, the amounts of $\mathrm{NO}$-induced respiratory inhibition and $\Delta \Psi_{\mathrm{m}}$ dissipation vary as a function of $\mathrm{O}_{2}$ concentration (Brown and Cooper, 1994). Using tanks of known $\mathrm{O}_{2}$ concentrations $(95,21,9$, and $1 \%)$ and an oxygenimpermeable experimental setup, we clamped the $\mathrm{pO}_{2}$ within the experimental chamber to known values and assessed the relationship between $\mathrm{pO}_{2}$ and the magnitude of NMDA-induced TMRM fluorescence loss. For each $\mathrm{O}_{2}$ concentration studied, we first recorded the level of fura-2 and TMRM fluorescence in $21 \%$ oxygen and then switched the perfusate to one equilibrated with a different $\mathrm{O}_{2}$ concentration for $5 \mathrm{~min}$ before administering NMDA. In the absence of NMDA, neither fura-2 nor TMRM fluorescence changed as a result of altering chamber $\mathrm{O}_{2}$ concentration. Importantly, however, we did observe that the lower the $\mathrm{pO}_{2}$ concentration, the more NMDA stimulation dissipated $\Delta \Psi_{\mathrm{m}}$ (Fig. 4). Correlation analysis revealed a significant, negative, linear relationship between $\mathrm{pO}_{2}$ and NMDA-induced $\Delta \Psi_{\mathrm{m}}$ dissipation magnitude $(r=0.27 ; p<0.01 ; n=111)$. Accordingly, the $\mathrm{O}_{2}$ dependence of this response supports the hypothesis that NMDA-induced NO production dissipates $\Delta \Psi_{\mathrm{m}}$ by competitively binding to cytochrome $c$ oxidase.

NMDA-induced NO production is regulated by $\Delta \Psi_{m}$ and depends on increases in $\left[\mathrm{Ca}^{2+}\right]_{\text {mito }}$

Because mitochondrial respiratory inhibition appears central to NO-induced $\Delta \Psi_{\mathrm{m}}$ dissipation in these neurons, we asked whether mitochondria themselves regulate NO production. We first assessed whether mitochondrial polarization is required for NO production by measuring NMDA-induced NO production in neurons in which $\Delta \Psi_{\mathrm{m}}$ was dissipated with the protonophore FCCP. To prevent the ATP consumption that accompanies uncoupling of oxidative phosphorylation from ATP synthesis, neurons were first incubated in oligomycin $(2 \mu \mathrm{g} / \mathrm{ml})$ for $3 \mathrm{~min}$, and the slope of DAF-FM fluorescence increase was measured. Next, cells were exposed to FCCP $(1 \mu \mathrm{M})$ for $3 \mathrm{~min}$, and the DAF-FM 


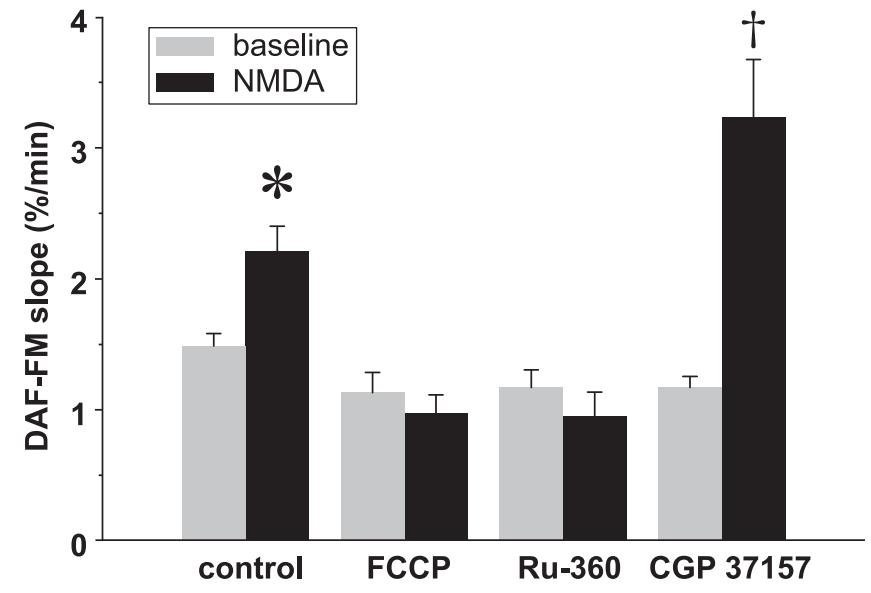

Figure 5. Inhibitors of mitochondrial $\mathrm{Ca}^{2+}$ cycling regulate NMDA-induced increases in NO production. Mean \pm SEM slopes of DAF-FM fluorescence increases at baseline and during NMDA, in control neurons and neurons treated with inhibitors of mitochondrial $\mathrm{Ca}^{2+}$ uptake and efflux. Preincubation with FCCP dissipates $\Delta \Psi_{m}$, eliminates the driving force for $\mathrm{Ca}^{2+}$ uptake into mitochondria, and blocks the NMDA-induced increase in N0. This blockade is mimicked by Ru-360, a specific inhibitor of mitochondrial Ca ${ }^{2+}$ uptake. CGP-37157, an inhibitor of mitochondrial $\mathrm{Na}^{+} / \mathrm{Ca}^{2+}$ exchange and, hence, $\mathrm{Ca}^{2+}$ efflux from mitochondria, markedly increases N0 production. Statistical comparisons are made between NMDA and control within each treatment group. ${ }^{*} p<0.05 ;{ }^{\dagger} p<0.01$.

fluorescence slope was measured again. Neither oligomycin alone nor oligomycin with FCCP significantly affected the slope of the DAF-FM fluorescence increase compared with untreated neurons (mean $\pm \mathrm{SEM}$, untreated, $1.36 \pm 0.07 \% / \mathrm{min}$; oligomycin, $1.38 \pm 0.13 \% / \mathrm{min}$; oligomycin plus FCCP, $1.13 \pm 0.15 ; n=35$; $p=$ NS). Finally, oligomycin and FCCP-treated neurons were exposed to NMDA (300 $\mu \mathrm{M})$ for 5 min. Under conditions of $\Delta \Psi_{\mathrm{m}}$ dissipation, the NMDA-induced increase in DAF-FM slope was completely blocked (mean \pm SEM, untreated, $2.63 \pm 0.16 \% / \mathrm{min}$ vs FCCP, $0.97 \pm 0.14 \% / \mathrm{min} ; n=35 ; p<0.02$ ) (Fig. 5). Accordingly, NMDA-induced NO production depends on either a polarized $\Delta \Psi_{\mathrm{m}}$ or conditions within the mitochondrion that are abolished with $\Delta \Psi_{\mathrm{m}}$ dissipation.

Dissipation of $\Delta \Psi_{\mathrm{m}}$ abolishes the driving force for $\mathrm{Ca}^{2+}$ entry into the mitochondria, resulting in loss of intramitochondrial free $\mathrm{Ca}^{2+}$ via the mitochondrial $\mathrm{Na}^{+} / \mathrm{Ca}^{2+}$ exchanger. Because neuronal NOS activity is $\mathrm{Ca}^{2+}$ dependent (Mayer et al., 1992), we hypothesized that the dependence of NMDA-induced NO production on $\Delta \Psi_{\mathrm{m}}$ reflects a dependence on increased mitochondrial matrix $\left[\mathrm{Ca}^{2+}\right]\left(\left[\mathrm{Ca}^{2+}\right]_{\text {mito }}\right)$. Accordingly, we compared the rates of DAF-FM fluorescence increases in neurons in which mitochondrial $\mathrm{Ca}^{2+}$ uptake and efflux were individually blocked. We first prevented mitochondrial $\mathrm{Ca}^{2+}$ uptake with $\mathrm{Ru}-360$, a cell-permeable, oxygen-bridged dinuclear ruthenium amine complex. In neurons incubated in Ru-360 (10 $\mu \mathrm{M}$ for $1 \mathrm{~h})$, the slope of DAF-FM fluorescence at baseline was not significantly different from untreated neurons. Similar to FCCP-treated neurons, in Ru-360-treated neurons, NMDA failed to increase the slope of DAF-FM fluorescence (Fig. 5), although the NMDAinduced $\left[\mathrm{Ca}^{2+}\right]_{\mathrm{i}}$ rise was unchanged. Thus, NMDA-induced NO production in these $\mathrm{P} 5$ neurons depends on $\mathrm{Ca}^{2+}$ influx into mitochondria. Next, mitochondrial $\mathrm{Ca}^{2+}$ efflux was blocked using CGP-37157 $(10 \mu \mathrm{m})$, a specific inhibitor of mitochondrial $\mathrm{Na}^{+} / \mathrm{Ca}^{2+}$ exchange, added after the first minute of the $5 \mathrm{~min}$ NMDA stimulus. Consistent with our hypothesis, in CGP37157-treated neurons, NMDA significantly increased the DAF-FM slope compared with neurons exposed to NMDA alone (mean \pm SEM, CGP-37157, $3.23 \pm 0.44 \% /$ min vs control, $2.63 \pm$ $0.16 \% / \mathrm{min} ; n=24 ; p<0.01$ ) (Fig. 5 ). Together, these data show that NMDA-induced NO production in these immature neurons depends on an increase in $\left[\mathrm{Ca}^{2+}\right]_{\text {mito }}$.

\section{Localization of neuronal NOS and NO production within mitochondria in $\mathrm{P} 5$ neurons}

Our finding that $\left[\mathrm{Ca}^{2+}\right]_{\text {mito }}$ regulates NO production suggested that these immature neurons harbor a $\mathrm{Ca}^{2+}$-regulated NOS within mitochondria. Accordingly, we looked for mitochondrial localization of NOS using double immunofluorescence: we simultaneously stained cultures using an anti-nNOS polyclonal antibody and a monoclonal anti-cytochrome oxidase antibody and used confocal microscopy to assess staining patterns and mitochondrial colocalization. P5 neurons did not demonstrate cytosolic staining for nNOS. Instead, punctate staining was seen in most somata that primarily excluded the nucleus. Simultaneous staining for cytochrome oxidase demonstrated that the majority of nNOS staining colocalized with mitochondria (Fig. 6, top). Assessment of the amount of fluorescence occurring from nonspecific binding of the anti-rabbit secondary antibody was performed with the secondary antibody alone. This staining revealed faint labeling of the nucleus only without mitochondrial colocalization. By demonstrating localization of nNOS to mitochondria, these studies provide anatomic evidence for the existence of a mitochondrially localized nNOS within these neurons.

Having found mitochondrial colocalization of nNOS in these neurons, we next looked for physiological evidence of mitochondrially localized NO production during NMDA stimulation using neurons loaded with DAF-FM and Mitofluor red 589, a $\Delta \Psi_{\mathrm{m}^{-}}$ independent mitochondrion-selective dye. To detect localized changes in DAF-FM fluorescence induced by NMDA, we imaged DAF-FM and Mitofluor red 590 every 20 s before and during NMDA $(300 \mu \mathrm{M})$ stimulation. Images were digitally deconvolved to remove out-of-focus light. To identify regions in which NMDA increased DAF-FM, we subtracted, on a pixel-by-pixel basis, the DAF-FM image obtained immediately before NMDA onset from each DAF-FM image obtained during NMDA stimulation. Within 40-60 s of the onset of NMDA, DAF-FM fluorescence appeared in highly localized regions within neurons and steadily increased over $5 \mathrm{~min}$. To assess mitochondrial localization of this fluorescence, subtracted images were superimposed onto the deconvolved Mitofluor red 589 images obtained at the same points during the experiment. This superimposition revealed that the initial DAF-FM fluorescence was highly localized to mitochondria, both in processes and soma, before spreading to nonmitochondrial regions of the soma (Fig. 6, bottom) (supplemental data, available at www.jneurosci.org as supplemental material). Identical experiments and analyses of NMDA-induced DAF-FM localization within Mitofluor red 589-identified mitochondria, performed using L-NAME-treated P5 neurons $(n=7)$, demonstrated no cellular DAF-FM increases. Furthermore, the identical image analysis used to detect mitochondrial DAF-FM increases failed to demonstrate any localization of DAF-FM within mitochondria. Thus, the combination of mitochondrial localization of NMDA-induced DAF-FM fluorescence and immunostaining evidence of mitochondrially localized nNOS provides anatomic and physiological evidence of NMDA-induced NO production within mitochondria in these hippocampal neurons. 


\section{NMDA-induced NO production} decreases vulnerability of $\mathrm{P} 5$ neurons to NMDA

Vulnerability to NMDA is decreased in neurons from immature animals compared with those from mature animals (Liu et al., 1996; Marks et al., 2000). Because protonophore-induced $\Delta \Psi_{\mathrm{m}}$ dissipation before excitotoxicity prevents neuronal death in vulnerable neurons (Stout et al., 1998), we hypothesized that the NOmediated $\Delta \Psi_{\mathrm{m}}$ dissipation we observed during NMDA in these P5 neurons contributed to their decreased vulnerability to NMDA. To assess the role of NO production in neuronal susceptibility to NMDA, NOS activity was blocked in neuronal cultures with L-NAME (100 $\mu \mathrm{M}$ for $3 \mathrm{~h})$. Then, half of the L-NAME-incubated cultures, as well as half of sister cultures not incubated in L-NAME, were exposed to NMDA $(300 \mu \mathrm{M})$ in ambient $(21 \%) \mathrm{O}_{2}$ for $20 \mathrm{~min}$, and survival was assessed $48 \mathrm{~h}$ later. Mean \pm SEM survival of control neurons was $96.3 \pm 4.2 \%$. In the absence of NMDA, survival of L-NAME-treated neurons was not significantly different from control neurons, and NMDA decreased survival by $\sim 25 \%$. L-NAME pretreatment significantly worsened survival after NMDA but by only $10 \%(n=36$ coverslips; $p<0.01$ ) (Fig. 7A).

Because we had found that the magnitude of NO-mediated $\Delta \Psi_{\mathrm{m}}$ dissipation markedly increased at progressively lower $\mathrm{O}_{2}$ concentrations, we predicted that the magnitude of NO-mediated neuroprotection would similarly depend on $\mathrm{O}_{2}$ concentration. Accordingly, we performed the identical survival assays on $\mathrm{P} 5$ neurons ( $n=18$ coverslips) at $3 \% \mathrm{O}_{2}$, an $\mathrm{O}_{2}$ concentration similar to that measured in rodent hippocampus in vivo (Feng et al., 1988; Buerk and Nair, 1993). Mean survival of $\mathrm{P} 5$ neurons after a $20 \mathrm{~min}$ exposure to control saline in $3 \% \mathrm{O}_{2}$ was $89.0 \pm$ $1.6 \%$, and survival of L-NAME-treated neurons was not significantly different from control. Remarkably, NMDA (300 $\mu \mathrm{M})$ did not reduce survival from control values (Fig. 7B). In L-NAME-treated neurons, however, NMDA markedly decreased neuronal survival to $43 \%$ of control ( $p<$ 0.01 ). Thus, at physiologic $\mathrm{O}_{2}$ tensions, NMDA-induced NO production provided robust protection from NMDA toxicity.

To better understand the mechanism of this NO-mediated neuroprotection, we assessed the role played by activation of soluble guanylate cyclase after NMDA-induced NO production. Neuronal cultures were treated with ODQ (10 $\mu \mathrm{M}$ for $30 \mathrm{~min})$ to inhibit soluble guanylate cyclase. Then, half of the ODQ-exposed cultures as well as half of sister cultures not exposed to ODQ were exposed to NMDA $(300 \mu \mathrm{M})$ in $21 \% \mathrm{O}_{2}$ for $20 \mathrm{~min}$, and survival anti-cytochrome oxidase

\section{overlay}
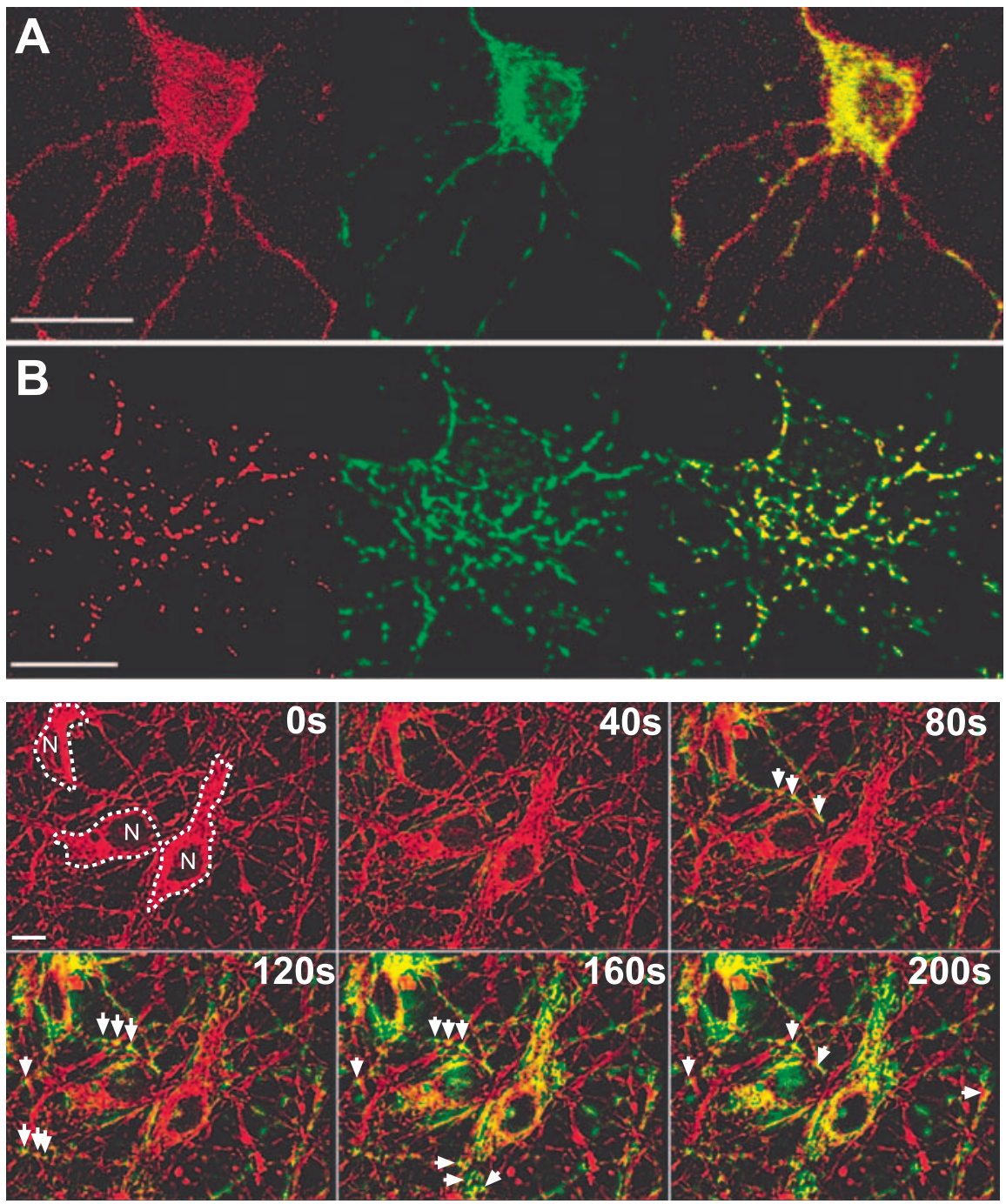

Figure 6. Anatomic and physiologic evidence of N0 production within mitochondria of P5 neurons. A, Staining patterns of immunoreactivity to nNOS and subunit I of mitochondrial cytochrome oxidase as visualized by confocal microscopy. nNOS binding (red) was identified with a fluorescent (Alexa 594) secondary antibody; cytochrome oxidase binding (green) was visualized through direct conjugation to Alexa 488. The yellow in the overlay indicates mitochondrial colocalization of nNOS. Scale bar, 20 $\mu \mathrm{m} . \boldsymbol{B}$, High-resolution confocal images of NOS and cytochrome oxidase immunoreactivity in the soma of a P5 neuron. Note the extensive colocalization of NOS with cytochrome oxidase and the almost complete absence of extramitochondrial NOS immunoreactivity. Scale bar, $10 \mu \mathrm{m}$. Bottom, Mitochondrial localization of NO production during NMDA. Neurons loaded with DAF-FM and Mitofluor red 589, a $\Delta \Psi_{\mathrm{m}}$-independent mitochondrial dye, were perfused with NMDA $(300 \mu \mathrm{m})$ for $5 \mathrm{~min}$. DAF-FM fluorescence that had accumulated before NMDA was removed from images obtained during NMDA stimulation by subtracting the DAF-FM image obtained immediately before NMDA from all subsequent images. Mitofluor (red) and DAF-FM (green) images were obtained sequentially every $20 \mathrm{~s}$, deconvolved to remove out-of-focus light, and overlaid to assess mitochondrial colocalization, which appears as yellow. This representative montage shows images obtained at different times (top right corner of each image) immediately before and during NMDA perfusion. Three neurons (outlined, with nuclei labeled N) are shown. By 80 s of NMDA stimulation, $\mathrm{N} 0$ is clearly visualized first within mitochondria (arrows), with little extramitochondrial staining. As NMDA stimulation continues, increasing numbers of mitochondria demonstrate $\mathrm{NO}$ production, with $\mathrm{NO}$ extending to nonmitochondrial regions only by $160 \mathrm{~s}$.

was assessed $48 \mathrm{~h}$ later. Survival after ODQ alone (mean \pm SEM, $101.2 \pm 1.8 \%$ of control) was not significantly different from control. As observed in other experiments, survival after NMDA (mean \pm SEM, $67.4 \pm 3.2 \%$ of control) was significantly decreased from control $(p<0.05)$. However, survival of ODQtreated neurons after NMDA (mean \pm SEM, 69.1 $\pm 6.1 \%$ of control) was not significantly different from survival of NMDAtreated neurons not exposed to ODQ ( $n=16$ coverslips). Thus, NO-mediated neuroprotection of immature hippocampal neu- 


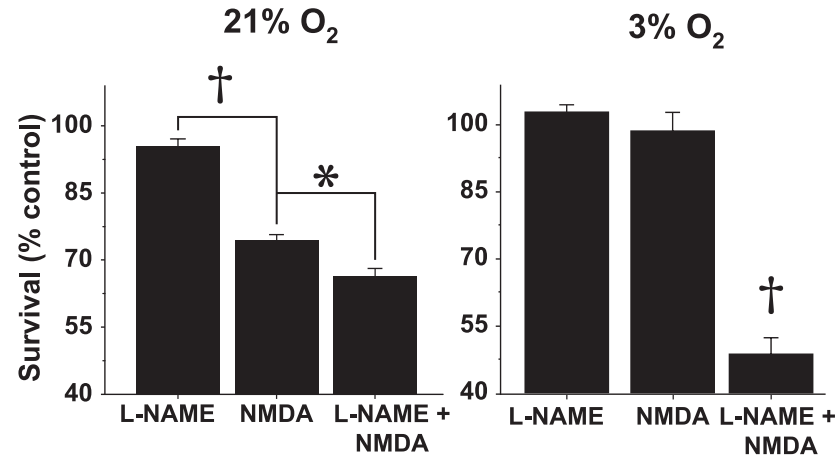

Figure 7. N0-induced protection of P5 neurons from NMDA toxicity is markedly enhanced at physiologic $\mathrm{O}_{2}$ tensions. Survival was quantified by live-dead assay $48 \mathrm{~h}$ after a 20 min exposure to NMDA and is expressed as a percentage of survival after exposure to bicarbonate-buffered saline alone (see Materials and Methods). $A, \ln 21 \% \mathrm{O}_{2}, \mathrm{~N} 0$ mediates modest neuroprotection. L-NAME incubation ( $100 \mu \mathrm{m}$ for $3 \mathrm{~h}$ ) alone does not alter survival. NMDA (300 $\mu \mathrm{m}$ for $20 \mathrm{~min}$ ) decreases survival at $48 \mathrm{~h}$ by $\sim 25 \%$. NOS blockade with L-NAME further decreases survival. $\boldsymbol{B}$, In $3 \% \mathrm{O}_{2}$, N0 mediates profound neuroprotection from NMDA. In contrast to $21 \% \mathrm{O}_{2}$, NMDA alone in $3 \% 0$, has virtually no effect on neuronal survival. However, NOS blockade with L-NAME markedly decreases survival to levels comparable with the effect of NMDA on P19 neurons (see Fig. 9). ${ }^{*} p<0.05{ }^{\dagger} p<0.01$.

rons after NMDA does not depend on activation of soluble guanylate cyclase.

\section{Mitochondria-regulated NO production decreases mitochondrial $\mathrm{Ca}^{2+}$ uptake}

We next assessed whether NO production, by virtue of its mild dissipation of $\Delta \Psi_{\mathrm{m}}$, decreases NMDA-induced mitochondrial $\mathrm{Ca}^{2+}$ uptake. We measured changes in $\left[\mathrm{Ca}^{2+}\right]_{\text {mito }}$ using rhod-2, a fluorescent cationic $\mathrm{Ca}^{2+}$ indicator that accumulates in mitochondria (Fig. 8A). To restrict our measurements to in-focus mitochondria, we analyzed digitally deconvolved images. To confirm that rhod-2 fluorescence reported changes in $\left[\mathrm{Ca}^{2+}\right]_{\text {mito }}$, we first measured changes in rhod-2 intensity in response to $\Delta \Psi_{\mathrm{m}}$ dissipation induced by oligomycin $(2 \mathrm{mg} / \mathrm{ml})$ and FCCP $(1 \mu \mathrm{M})$. This mitochondrial inhibition abruptly and uniformly decreased mitochondrial rhod-2 fluorescence to background levels. Subsequently, oligomycin and FCCP were applied at the end of every rhod-2 experiment with the same results. Next, we blocked mitochondrial $\mathrm{Ca}^{2+}$ uptake with $\mathrm{Ru}-360$ incubation $(10 \mu \mathrm{M}$ for $1 \mathrm{~h})$ and applied NMDA $(300 \mu \mathrm{M})$ for $5 \mathrm{~min}$. In contrast with untreated neurons (see below), Ru-360-treated neurons failed to demonstrate a significant increase in mean peak rhod-2 fluorescence during NMDA (mean \pm SEM, $3.7 \pm 1.4 \%$; $n=7$ ) (Fig. $8 C$ ). Thus, rhod-2 reliably reported changes in $\left[\mathrm{Ca}^{2+}\right]_{\text {mito }}$.

We next measured NMDA-induced increases in $\left[\mathrm{Ca}^{2+}\right]_{\text {mito }}$ in the presence and absence of previous nNOS blockade $(100 \mu \mathrm{M}$ L-NAME for $3 \mathrm{~h}$ ). Mitochondrial rhod-2 fluorescence was stable before NMDA. During NMDA stimulation, rhod-2 fluorescence abruptly increased (Fig. $8 \mathrm{~B}$ ). In control neurons, rhod-2 fluorescence increased by an average of $17.0 \pm 2.5 \%$ (mean \pm SEM; $n=$ 14) and remained elevated during NMDA, returning to baseline over the subsequent 5 min (Fig. 7B). In L-NAME-treated neurons, however, the rhod-2 fluorescence increase was almost twice the control increase (mean \pm SEM, $30.0 \pm 2.8 \% ; n=25 ; p<$ 0.01 ) (Fig. $8 B, C$ ). Furthermore, rhod-2 remained elevated above baseline for 5-7 min longer than control neurons. Thus, NMDAinduced NO production decreased the magnitude of the $\left[\mathrm{Ca}^{2+}\right]_{\text {mito }}$ rise and shortened the length of time during which $\left[\mathrm{Ca}^{2+}\right]_{\text {mito }}$ was elevated.
To obtain additional evidence that NMDA-induced NO production decreases mitochondrial $\mathrm{Ca}^{2+}$ uptake, we stimulated L-NAME-treated and control neurons with NMDA and then measured the amount of $\mathrm{Ca}^{2+}$ released into the cytosol after FCCP-induced $\Delta \Psi_{\mathrm{m}}$ dissipation according to the method of Brocard et al. (2001). FCCP-induced changes in $\left[\mathrm{Ca}^{2+}\right]_{\text {cytosol }}$ were measured with the low-affinity $\mathrm{Ca}^{2+}$ indicator fura-FF. NMDA (300 $\mu \mathrm{M}$ for $5 \mathrm{~min}$ ) induced an increase in fura-FF ratio that declined after NMDA removal. In control neurons, FCCP, applied 5 min after the end of NMDA, transiently increased fura-FF ratios in a small percentage of neurons; in the majority of control neurons, the fura-FF ratio continued to decline (Fig. 8D). In contrast, in neurons subjected to nNOS blockade, FCCP caused a marked increase in fura-FF ratio in all neurons studied (Fig. 8D). To quantify this $\mathrm{Ca}^{2+}$ release, we measured the baselinesubtracted areas under the curves (AUCs) of fura-FF during FCCP: L-NAME-treated neurons exhibited a significantly larger mean AUC compared with control neurons $(n=61 ; p<0.01)$ (Fig. $8 E$ ), indicating that NOS blockade increases the amount of $\mathrm{Ca}^{2+}$ released from the mitochondria and, hence, the amount of $\Delta \Psi_{\mathrm{m}}$-dependent $\mathrm{Ca}^{2+}$ uptake during NMDA. These data, together with the increased NMDA-induced rhod-2 transients in nNOS-inhibited neurons, indicate that endogenous NO decreases mitochondrial $\mathrm{Ca}^{2+}$ uptake in P5 neurons during NMDA.

\section{In neurons from mature rats, NO does not mediate NMDA- induced $\Delta \Psi_{m}$ dissipation but does mediate NMDA toxicity}

In contrast to protecting neurons from NMDA toxicity, as seen in immature neurons, NMDA-induced NO production has been shown to kill neurons in the brains of mature animals, as well as in cultured embryonic neurons maintained in vitro for $>10 \mathrm{~d}$ (Dawson et al., 1991; Schulz et al., 1995; Keelan et al., 1999). We wanted, therefore, to define how the role of NMDA-induced NO production changes during postnatal development. Accordingly, we compared our findings in P5 neurons with those of hippocampal neurons cultured from P19 rats and studied at the same time in vitro. These neurons from mature animals demonstrate much greater vulnerability to NMDA toxicity than do P5 neurons (Marks et al., 2000).

We first assessed the extent of NMDA-induced $\Delta \Psi_{\mathrm{m}}$ dissipation and whether NO production played a role in any dissipation. In contrast to the modest $\Delta \Psi_{\mathrm{m}}$ dissipation seen in neurons from 5 -d-old animals ( $-24.1 \pm 5.4 \%$, mean \pm SEM; see above), neurons from 19-d-old animals demonstrated almost complete $\Delta \Psi_{\mathrm{m}}$ dissipation during NDMA (mean peak dissipation, $-73.8 \pm$ $6.6 \% ; n=6$ ) (Fig. 9A). This dissipation typically lasted for 30-40 min. In marked contrast to P5 neurons, blockade of NOS activity with L-NAME pretreatment (100 $\mu \mathrm{M}$ for $3 \mathrm{~h}$ ) failed to alter the magnitude or duration of NMDA-induced $\Delta \Psi_{\mathrm{m}}$ dissipation $(n=$ 35) (Fig. 9A). Because this greater $\Delta \Psi_{\mathrm{m}}$ dissipation in P19 neurons compared with that of $\mathrm{P} 5$ neurons could be attributable to larger NMDA-induced $\left[\mathrm{Ca}^{2+}\right]_{\mathrm{i}}$ increases, we assessed the magnitude of the $\left[\mathrm{Ca}^{2+}\right]_{\mathrm{i}}$ rise after NMDA with fura-FF. Surprisingly, mean peak fura-FF ratios during NMDA were much smaller in these mature neurons $(0.33 \pm 0.01$, mean \pm SEM; $n=14)$ (Fig. $9 B)$ compared with those ratios in P5 neurons (1.23 \pm 0.28 , mean \pm SEM; see above). These smaller peak ratios suggest that NMDA does not elevate $\left[\mathrm{Ca}^{2+}\right]_{\text {cytosol }}$ in P19 neurons to levels achieved in $\mathrm{P} 5$ neurons. However, greater $\mathrm{Ca}^{2+}$ loading into P19 neurons during NMDA compared with P5 neurons cannot be excluded as a contributory mechanism to the increased $\Delta \Psi_{\mathrm{m}}$ 
dissipation without electrophysiological measurement of whole-cell current densities. Nonetheless, these data demonstrate that NO production does not mediate the profound $\Delta \Psi_{\mathrm{m}}$ dissipation that occurs in these mature neurons during NMDA.

Having obtained evidence that NO does not mediate the NMDA-induced $\Delta \Psi_{\mathrm{m}}$ dissipation in mature neurons, we assessed what role NO plays in determining neuronal survival after NMDA. We measured survival $48 \mathrm{~h}$ after NMDA in cultures exposed and unexposed to previous nNOS blockade (L-NAME, $100 \mu \mathrm{M}$ for $3 \mathrm{~h}$ ). We first performed these studies ( $n=$ 24 coverslips) in $21 \% \mathrm{O}_{2}$. Baseline survival of P19 neurons after a $20 \mathrm{~min}$ exposure to saline was $71.6 \pm 0.3 \%$ (mean \pm SEM). In the absence of NMDA, L-NAME had no statistically significant effect on survival. After NMDA in the absence of L-NAME, fewer than $35 \%$ of neurons survived ( $p<$ 0.01 ) (Fig. 9C). However, in stark contrast to the neuroprotection seen in P5 neurons, L-NAME pretreatment provided marked neuroprotection, increasing neuronal survival to levels not significantly different from control neurons (Fig. 9C).

Because, in P5 neurons, we had found that $\mathrm{NO}$ effects were increased at lower $\mathrm{O}_{2}$ tensions, we confirmed that NO-induced neurotoxicity in P19 neurons did not change at a lower $\mathrm{O}_{2}$ tension. We performed the identical survival studies using $3 \% \mathrm{O}_{2}$-equilibrated solutions $(n=18$ coverslips). Control survival of P19 neurons $48 \mathrm{~h}$ after a $20 \mathrm{~min}$ exposure to saline was $76.7 \pm 0.02 \%$, slightly higher than under $21 \% \mathrm{O}_{2}$. Survival after NMDA in $3 \% \mathrm{O}_{2}$ decreased markedly compared with control $(p<0.01)$ and to a similar extent seen in $21 \% \mathrm{O}_{2}$. Similarly, L-NAME pretreatment provided marked neuroprotection, just as observed in $21 \% \mathrm{O}_{2}$, with survival after NMDA not significantly different from control (Fig. 9D). Thus, in P19 neurons, and in contrast to $\mathrm{P} 5$ neurons, NO production mediates much of the toxicity of NMDA.

\section{NMDA induces greater NO production in $\mathrm{P} 19$ neurons}

The contrast between NO-mediated neuroprotection in $\mathrm{P} 5$ neurons and NOinduced neurotoxicity in P19 neurons suggested that P19 neurons may differ from P5 neurons in either the magnitude or intracellular location of NMDA-induced NO production. Therefore, we first measured changes in NO production during NMDA using DAF-FM and linear regression (Fig. 10). The mean baseline slope of DAF-FM fluorescence increase in P19 neurons was approximately half of that seen in P5 neurons $(n=26 ; p<$ 0.01). Similar to P5 neurons, NMDA induced a significantly greater DAF-FM slope compared with baseline (Fig. 10). How-
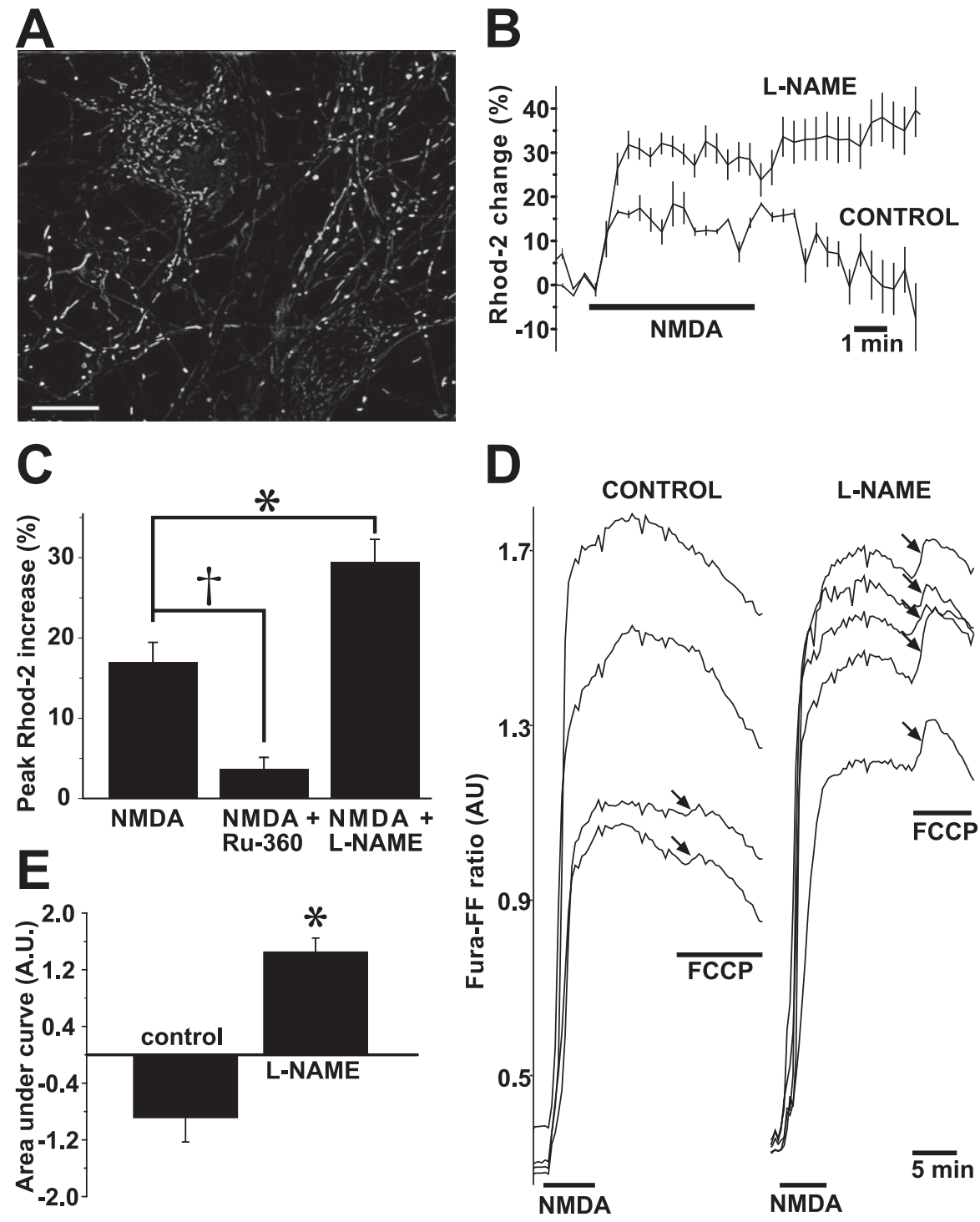

Figure 8. NMDA-induced NO production decreases mitochondrial $\mathrm{Ca}^{2+}$ loading. $\boldsymbol{A}$, Neurons loaded with rhod-2. This image and all images used for quantification were deconvolved to remove out-of-focus light. Scale bar, $20 \mu \mathrm{m}$. $\boldsymbol{B}$, NOS blockade with L-NAME (100 $\mu \mathrm{m}$ for $3 \mathrm{~h}$ ) induces greater increases in $\left[\mathrm{Ca}^{2+}\right]_{\text {mito }}$ (reported by rhod-2) compared with control neurons. Two representative experiments are overlaid for comparison. Each trace is the average of five neurons. Vertical lines represent SDs. In addition to the greater NMDA-induced rhod-2 increase in the L-NAME-treated neurons, note also that, in the L-NAME-treated neurons, $\left[\mathrm{Ca}^{2+}\right]_{\text {mito }}$ has not declined by $5 \mathrm{~min}$ after the end of NMDA, whereas, in control neurons, $\left[\mathrm{Ca}^{2+}\right]_{\text {mito }}$ has returned to baseline levels. $C$, Population summary of mean peak rhod-2 increases during NMDA stimulation comparing control neurons with neurons incubated in Ru-360 (10 $\mu \mathrm{m}$ for $1 \mathrm{~h}$ ), a specific inhibitor of mitochondrial $\mathrm{Ca}^{2+}$ uptake, and neurons incubated in L-NAME. As predicted, Ru-360 blocks the NMDA-induced rhod-2 rise, whereas nNOS inhibition with L-NAME significantly increases it. D, NOS inhibition increases mitochondrial $\mathrm{Ca}^{2+}$ loading during NMDA. Mitochondrial $\mathrm{Ca}^{2+}$ loading was quantified by stimulating control and L-NAME-treated neurons (100 $\mu \mathrm{m}$ for $3 \mathrm{~h}$ ) with NMDA (300 $\mu \mathrm{m}$ for $5 \mathrm{~min}$ ) and then measuring changes in $\left[\mathrm{Ca}^{2+}\right]_{\text {cytosol }}$ after FCCP-induced $\Delta \Psi_{\mathrm{m}}$ dissipation. Changes in $\left[\mathrm{Ca}^{2+}\right]_{\text {cytosol }}$ were reported with fura-FF. With this dye $\left(K_{\mathrm{d}}\right.$ for $\mathrm{Ca}^{2+}$ of $\left.5.5 \mu \mathrm{M}\right)$, FCCP causes a small fluorescence increase in a few control neurons. In contrast, NOS-inhibited neurons exhibit marked fura-FF increases in all neurons, demonstrating greater mitochondrial $\mathrm{Ca}^{2+}$ release and, hence, greater mitochondrial $\mathrm{Ca}^{2+}$ loading during NMDA. $\boldsymbol{E}$, Quantification of the fura-FF AUC during FCCP stimulation. In L-NAME-treated neurons, the AUC is significantly greater than in control neurons. The AUC is negative in control neurons because the fura-FF fluorescence continued to fall in most neurons during FCCP. ${ }^{*} p<0.05 ;{ }^{\dagger} p<0.10$.

ever, the mean slope increase during NMDA was not significantly different from that observed in $\mathrm{P} 5$ neurons (mean \pm SEM, P19, $3.1 \pm 0.4 \% / \mathrm{min}$ vs $\mathrm{P} 5,2.6 \pm 0.7 \% / \mathrm{min} ; n=26 ; p=0.18)$. To reveal the extent of any $\mathrm{NO}$ consumption by $\mathrm{O}_{2}{ }^{\circ}$ during NMDA at this maturational stage, we next pretreated P19 neurons with MnTBAP: MnTBAP-treated P19 neurons demonstrated a significantly greater increase in mean DAF-FM slope during NMDA 

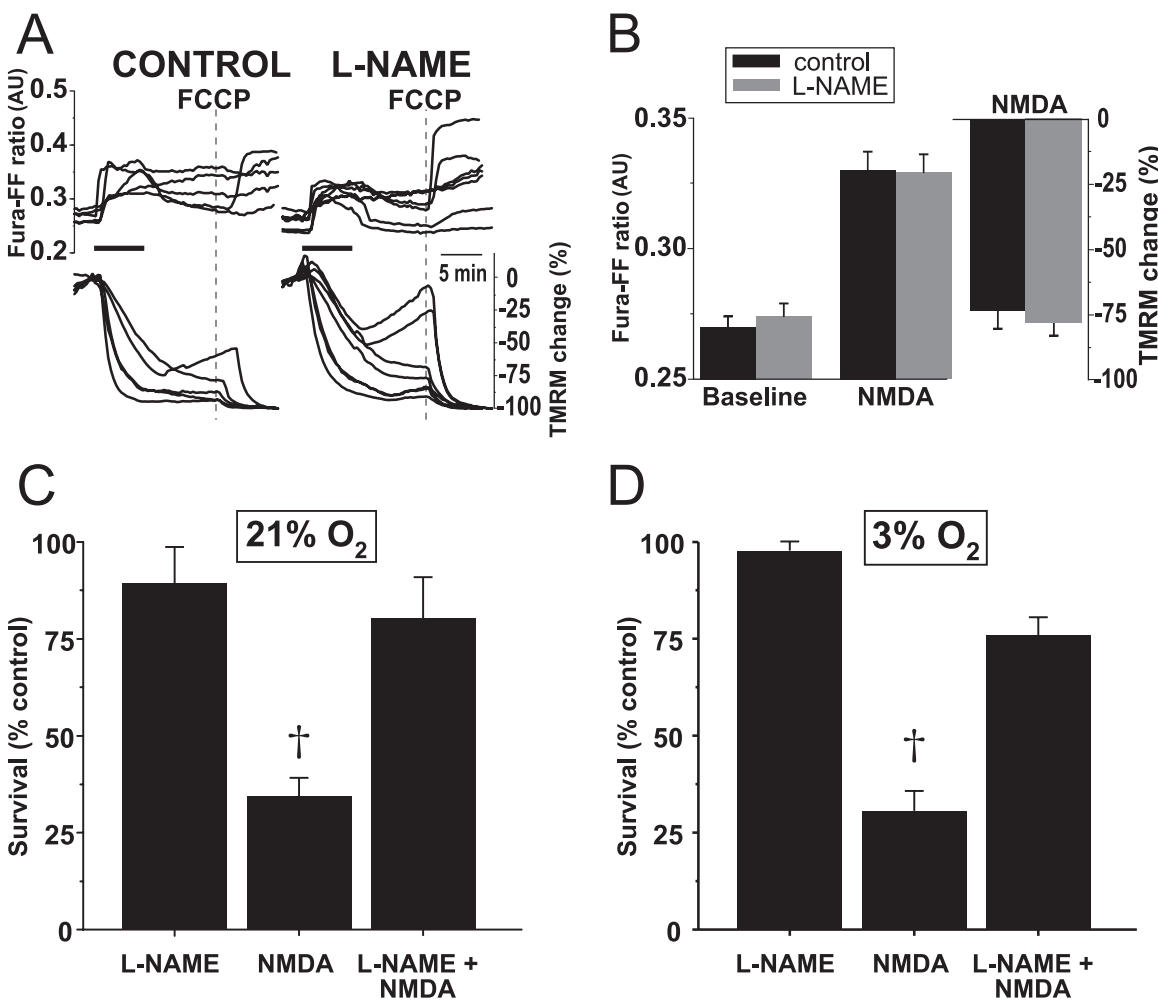

Figure 9. In hippocampal neurons from P19 rats, NO production does not mediate the marked, NMDA-induced $\Delta \Psi_{\mathrm{m}}$ dissipation but does induce widespread neuronal death after NMDA. $\boldsymbol{A}$, Simultaneous measures over time of NMDA-induced changes in $\left[\mathrm{Ca}^{2+}\right]_{\mathrm{i}}$ (fura-FF, $K_{\mathrm{d}}$ of $5.5 \mu \mathrm{m}$ ) and $\Delta \Psi_{\mathrm{m}}$ (TMRM) in the absence (left) and presence (right) of L-NAME (100 $\mu \mathrm{m}$ for $3 \mathrm{~h}$ ). Maximal $\Delta \Psi_{\mathrm{m}}$ dissipation is induced with FCCP (dotted line) at the end of each experiment. In contrast with P5 hippocampal neurons, NMDA induces profound $\Delta \Psi_{\mathrm{m}}$ dissipation. L-NAME fails to block this dissipation. $\boldsymbol{B}$, Population summary of mean peak $\left[\mathrm{Ca}^{2+}\right]$ increases and $\Delta \Psi_{m}$ dissipation during NMDA in the presence and absence of L-NAME. The magnitudes of neither the $\left[\mathrm{Ca}^{2+}\right]_{i}$ increases nor the $\Delta \Psi_{m}$ dissipation differ significantly between control and L-NAME-treated neurons. C, N0 mediates neuronal death in $\mathrm{P} 19$ neurons from NMDA in $21 \% \mathrm{O}_{2}$. Survival was quantified by live-dead assay $48 \mathrm{~h}$ after a 20 min exposure to NMDA (300 $\mu \mathrm{M}$ for $20 \mathrm{~min}$ ) and is expressed as a percentage of survival after exposure to control, bicarbonate-buffered saline alone (see Materials and Methods). L-NAME incubation alone does not alter survival. NMDA decreases survival to $25 \%$ of control. L-NAME pretreatment prevents the majority of NMDA-induced death. $\boldsymbol{D}$, When applied in $3 \% 0_{2}$, NMDA induces the same degree of neuronal death seen in $21 \% \mathrm{O}_{2}$. The marked neuroprotection conferred by L-NAME pretreatment before NMDA exposure in $3 \% \mathrm{O}_{2}$ demonstrates that physiologic $\mathrm{O}_{2}$ tension does not affect the neurotoxic effects of NMDA-induced N0 production. ${ }^{\dagger} p<0.01$.

compared with untreated neurons, indicating significant peroxynitrite production during NMDA. Most importantly, the mean DAF-FM slope was $\sim 30 \%$ larger than that observed in MnTBAP-treated P5 neurons $(n=24 ; p<0.05)$. Thus, NMDA induces significantly greater NO production during NMDA in P19 neurons compared with P5 neurons. These data also suggest that NMDA induces greater peroxynitrite formation in mature neurons than in immature neurons.

\section{NOS expression is localized to the cytosol in P19 neurons} Having obtained evidence of greater NMDA-induced NO production in P19 neurons, we next assessed whether this NO production was regulated by $\Delta \Psi_{\mathrm{m}}$. Neurons were exposed to oligomycin $(2 \mu \mathrm{g} / \mathrm{ml})$ and FCCP $(1 \mu \mathrm{M})$, followed by NMDA, exactly as done with P5 neurons. Oligomycin with FCCP did not significantly alter the baseline slope of DAF-FM fluorescence. Most importantly, after oligomycin/FCCP, NMDA significantly increased DAF-FM slopes to levels equal to those observed in the absence of these mitochondrial inhibitors (Fig. 10). Thus, unlike P5 neurons, NMDA-induced NO production does not depend on intact mitochondrial $\Delta \Psi_{\mathrm{m}}$.

The lack of dependence of NO production on $\Delta \Psi_{\mathrm{m}}$ suggested that NOS expression in P19 neurons was not localized to mitochondria, as we had observed in P5 neurons. Accordingly, we performed double immunofluorescence for nNOS and cytochrome oxidase of P19 neurons and obtained high-resolution confocal images to assess colocalization. In contrast to P5 neurons, nNOS immunoreactivity was evenly distributed throughout the cytoplasm. In fact, double staining for cytochrome oxidase revealed no mitochondrial colocalization of NOS immunoreactivity (Fig. 11). This absence of mitochondrial localization of nNOS, together with the lack of mitochondrial regulation of $\mathrm{NO}$ production during NMDA, indicate that, by $19 \mathrm{~d}$ of age, there is little, if any, mitochondrial NO production during NMDA and suggest that hippocampal neurons no longer express a mitochondrially localized nNOS.

\section{Discussion}

We report here that, in hippocampal neurons from $\mathrm{P} 5$ rats, $\mathrm{Ca}^{2+}$-dependent $\mathrm{NO}$ production within mitochondria mediates the $\Delta \Psi_{\mathrm{m}}$ dissipation seen during NMDA stimulation. This mitochondrial NO production decreases mitochondrial $\mathrm{Ca}^{2+}$ uptake during NMDA and, at $\mathrm{O}_{2}$ tensions characteristic of hippocampus in vivo, mediates much of the decreased vulnerability to NMDA seen in neurons from immature animals (Liu et al., 1996; Marks et al., 1996, 2000). In contrast, in neurons from P19 rats, which are highly sensitive to NMDA, NMDA induces NO production by cytosolic NOS, which mediates their vulnerability to NMDA. Thus, important developmental changes in vulnerability to NMDA are mediated by a change in NOS expression from mitochondria to the cytosol.

In this study, NMDA-induced $\left[\mathrm{Ca}^{2+}\right]_{\mathrm{i}}$ elevations did not increase during postnatal development. Therefore, increased bulk cytosolic $\left[\mathrm{Ca}^{2+}\right]_{\mathrm{i}}$ cannot explain the increased vulnerability that accompanies maturation. Instead, P19 neurons exhibit profound $\Delta \Psi_{\mathrm{m}}$ dissipation compared with neurons from younger, less vulnerable animals. These developmental changes contrast with excitotoxic vulnerability seen in cultured embryonic hippocampal neurons in which the onset of vulnerability occurs after 10-14 d in vitro (Frandsen and Schousboe, 1990; Keilhoff and Erdo, 1991) through progressively increasing expression of the NMDA receptor (Mattson et al., 1991; Xia et al., 1995; Sinor et al., 1997).

In P5 neurons, we found the magnitude of the NO-mediated TMRM decrease during NMDA to be on the order of $25 \%$ from baseline. This decrease, being proportional to the change in mitochondrial TMRM concentration, is likely an overestimate of the magnitude of $\Delta \Psi_{\mathrm{m}}$ dissipation and may correspond to a decrease of, at most, $10 \mathrm{mV}$ (Nicholls and Budd, 2000). In contrast, in P19 neurons, NO did not mediate the profound $\Delta \Psi_{\mathrm{m}}$ dissipation seen during NMDA, although NOS blockade prevented the subsequent widespread neuronal death. Our results do not shed light on the mechanism of the NMDA-induced mitochondrial 


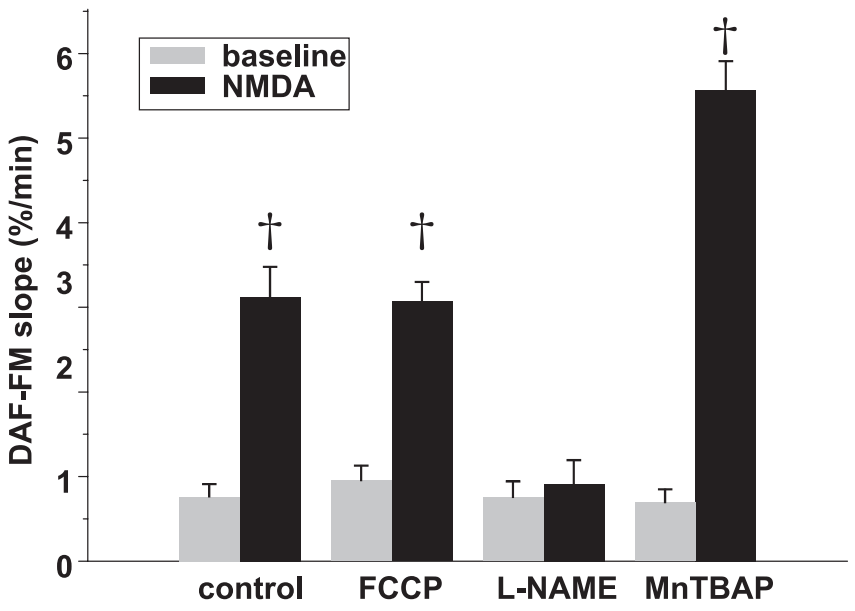

Figure 10. NMDA-induced increases in N0 production in P19 neurons are not regulated by $\Delta \Psi_{\mathrm{m}}$. Mean \pm SEM slopes of DAF-FM fluorescence increases at baseline and during NMDA in control P19 neurons and neurons treated with the noted inhibitors. Unlike in P5 neurons, preincubation with FCCP does not block the NMDA-induced increase in NO. NOS blockade with L-NAME (100 $\mu \mathrm{M}$ for $3 \mathrm{~h}$ ) prevents the NMDA-induced increase in mean DAF slope. MnTBAP treatment, by increasing NO availability, reveals significantly increased NO production during NMDA. Statistical comparisons are made between NMDA and control within each treatment group. ${ }^{\dagger} p<0.01$.

\section{anti-nNOS}

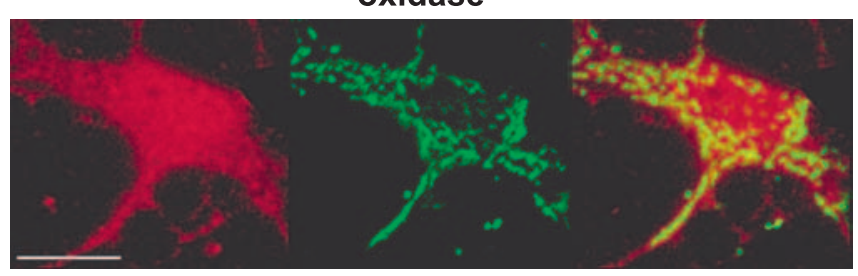

Figure 11. NOS expression in P19 neurons is cytosolic and does not colocalize to mitochondria. High-resolution confocal images of NOS (red) and cytochrome oxidase (green) immunoreactivity in the soma of a P19 neuron. Yellow in the overlay would indicate mitochondrial colocalization of nNOS. Scale bar, $10 \mu \mathrm{m}$.

depolarization in P19 neurons. However, they indicate that, in the absence of NO generation, 30-40 min periods of mitochondrial dysfunction is well tolerated by these neurons, suggesting that glycolysis can support ATP generation during such periods.

NO-mediated $\Delta \Psi_{\mathrm{m}}$ dissipation has been observed in cortical (Almeida et al., 1999) and hippocampal (Keelan et al., 1999) embryonic neuron cultures after glutamate, accompanied by decreased $\mathrm{O}_{2}$ consumption. NO-induced $\Delta \Psi_{\mathrm{m}}$ dissipation occurs from inhibition of mitochondrial respiration (Koivisto et al., 1997; Brorson et al., 1999; Ushmorov et al., 1999): at nanomolar concentrations, $\mathrm{NO}$ competes with $\mathrm{O}_{2}$ for binding to cytochrome oxidase; at micromolar NO concentrations, other metabolic enzymes are irreversibly inhibited (Brown, 1999). We observed progressively greater $\Delta \Psi_{\mathrm{m}}$ dissipations as $\mathrm{O}_{2}$ concentration decreased from $21 \% \mathrm{O}_{2}(150$ torr, $336 \mu \mathrm{M})$ to $1 \% \mathrm{O}_{2}$ ( 7 torr, $16 \mu \mathrm{M}$ ). This $\mathrm{O}_{2}$-dependent dissipation is consistent with competitive inhibition of cytochrome oxidase by NO. However, it is possible that $\mathrm{O}_{2}$ or $\mathrm{O}_{2}$-dependent reactions decreased the availability of $\mathrm{NO}$ at higher $\mathrm{O}_{2}$ tensions, resulting in decreased $\Delta \Psi_{\mathrm{m}}$ dissipation. Nonetheless, similar $\mathrm{pO}_{2}$-dependent changes occur in isolated mitochondria, in which half-maximal inhibition of respiration occurs at progressively lower $\mathrm{NO}$ concentrations as the $\mathrm{O}_{2}$ concentration is lowered (Koivisto et al., 1997).
Physiologic $\mathrm{pO}_{2}$ in hippocampus is $14-21$ torr $(31-47 \mu \mathrm{M})$ (Feng et al., 1988; Buerk and Nair, 1993), much lower than the 150 torr of $\mathrm{pO}_{2}$ in room air in which in vitro studies of cultured neurons are usually performed. Hence, the importance of NOmediated $\Delta \Psi_{\mathrm{m}}$ dissipation after NMDA in hippocampus in vivo has likely been underestimated. The marked increase in NOmediated neuroprotection of P5 neurons that becomes apparent at physiologic $\mathrm{O}_{2}$ tensions also underscores the importance of assessing environmental $\mathrm{O}_{2}$ tensions in determining $\mathrm{NO}$ effects.

In $\mathrm{P} 5$ neurons, NMDA-induced $\mathrm{NO}$ production was regulated by $\left[\mathrm{Ca}^{2+}\right]_{\text {mito }}$, as revealed by pharmacologic manipulation of mitochondrial $\mathrm{Ca}^{2+}$ uptake and efflux pathways. Mitochondrial $\mathrm{Ca}^{2+}$ uptake has been similarly reported to regulate $\mathrm{Ca}^{2+}$ dependent mitochondrial NO production in permeabilized bovine vascular endothelial cells (Dedkova et al., 2003). To support our pharmacologic data, we obtained immunohistochemical evidence of nNOS localized to mitochondria as well as physiological evidence of DAF-FM conversion within mitochondria during NMDA. Together, these observations argue strongly for functional mitochondrial NOS in these immature neurons. In mature neurons, our data demonstrate cytosolic, not mitochondrial, NOS expression. Cytosolic and mitochondrial NOS expression have been shown to be strongly regulated during postnatal brain development: whereas cytosolic NOS expression increases during the first 3 months of postnatal life, mitochondrially localized (mtNOS) expression is highest immediately before birth and during the first week of life (Riobo et al., 2002), becoming undetectable in the adult (Lacza et al., 2004).

mtNOS has been extensively characterized in liver, heart, and kidney (Ghafourifar and Richter, 1997; Bringold et al., 2000; Lacza et al., 2001; Boveris et al., 2003; Giulivi, 2003). Producing 1-2 nmol NO per minute per milligram of protein in intact mitochondria (Giulivi et al., 1998), mtNOS has been localized to mitochondria using biochemical and porphyrinic microsensor techniques (Kanai et al., 2001) and by immunohistochemical colocalization. Its mitochondrial localization may be attributable to myristoylation (Elfering et al., 2002). Although mtNOS has been implicated in metabolic control, as well as coupling of metabolic rate to local $\mathrm{O}_{2}$ concentrations, it has not, to our knowledge, been identified previously as protecting mitochondria from $\mathrm{Ca}^{2+}$ overload.

Compared with non-NMDA sources, equivalent NMDAinduced $\mathrm{Ca}^{2+}$ loading of embryonic cortical neurons is much more toxic (Sattler et al., 1998) and is linked to coupling of NMDA receptors to cytosolic NOS activation via postsynaptic density-95 (PSD-95), a member of the membrane-associated guanylate cyclase family (Sattler et al., 1999; Aarts et al., 2002). In P5 neurons, the absence of $\Delta \Psi_{\mathrm{m}}$ dissipation and DAF-FM changes after plasma membrane depolarization-induced $\left[\mathrm{Ca}^{2+}\right]_{\mathrm{i}}$ elevations suggests similar dependence of NO production on NMDA receptor activation. However, the absence of cytosolic NOS in these immature neurons suggests that a PSD-95/NOS interaction is unlikely. Instead, the dependence of NO production on mitochondrial $\mathrm{Ca}^{2+}$ uptake suggests that NMDA receptor activation leads to $\left[\mathrm{Ca}^{2+}\right]$ increases around mitochondria, as observed in neurons (Baron et al., 2003) and non-neuronal cells (Montero et al., 2000; Filippin et al., 2003).

Mitochondrial $\mathrm{Ca}^{2+}$ uptake is required for excitotoxic neuronal death (Dessi et al., 1995; Budd and Nicholls, 1996; Stout et al., 1998; Pivovarova et al., 2004). In P5 neurons, NO-mediated $\Delta \Psi_{\mathrm{m}}$ dissipation during NMDA decreased mitochondrial $\mathrm{Ca}^{2+}$ uptake and provided profound neuroprotection at physiologic $\mathrm{O}_{2}$ tensions. These findings provide additional support for the hypothesis that the initial $\mathrm{Ca}^{2+}$ influx during NMDA results in activa- 
tion of NO production, NO-induced $\Delta \Psi_{\mathrm{m}}$ dissipation, and subsequent reduction of $\mathrm{Ca}^{2+}$ influx.

In P5 neurons, L-NAME increased NMDA-induced mitochondrial $\mathrm{Ca}^{2+}$ uptake and abolished the $\Delta \Psi_{\mathrm{m}}$ dissipation seen during the same period. How could mitochondrial $\mathrm{Ca}^{2+}$ uptake increase without simultaneous $\Delta \Psi_{\mathrm{m}}$ dissipation? Of the somal mitochondria contributing to our TMRM measurement, only those mitochondria located near NMDA receptors may have been exposed to sufficiently high local $\mathrm{Ca}^{2+}$ concentrations to induce enough mitochondrial $\mathrm{Ca}^{2+}$ uptake to dissipate $\Delta \Psi_{\mathrm{m}}$. A recent study of the relationship between extramitochondrial $\mathrm{Ca}^{2+}$ concentration and $\Delta \Psi_{\mathrm{m}}$ collapse using two-photon excitation imaging in cultured mouse Purkinje neurons demonstrated that, in response to induced $\mathrm{Ca}^{2+}$ increases, $\Delta \Psi_{\mathrm{m}}$ dissipation in individual mitochondria occurs in an all-or-nothing manner, depending on whether the local $\mathrm{Ca}^{2+}$ concentration exceeds $10 \mu \mathrm{M}$ (Hayakawa et al., 2005). Accordingly, the contribution of this subpopulation to the TMRM signal recorded from the whole soma may, in P5 neurons, be too small to be detected. In addition, the decreased expression of NMDA receptor subunit NR1 in 5-dold rats compared with 19-d-old rats (Monyer et al., 1994; Riva et al., 1994) may result in decreased numbers of NMDA receptors being located near mitochondria in P5 neurons. However, the magnitudes of NMDA-induced $\left[\mathrm{Ca}^{2+}\right]_{\mathrm{i}}$ elevations observed in the two age groups do not support decreased bulk cytosolic $\mathrm{Ca}^{2+}$ entry during NMDA in P5 neurons.

NO-mediated neurotoxicity after NMDA has been well demonstrated to occur in vivo and in vitro (Dawson et al., 1991; Huang et al., 1994; Dawson et al., 1996; Keelan et al., 1999); our observation that NMDA kills P19 neurons via NO is, therefore, unsurprising. Nitric oxide and its reactive metabolites have well described chemistry, including binding to metal centers of proteins, $S$-nitrosylation of reduced cysteine residues, and nitration of lipids and aromatic amino acids (for review, see Ischiropoulos and Gow, 2005). In P19 neurons, NO appears to take on a detrimental role, perhaps as a result of its cytosolic distribution or because of greater NO production during NMDA, as we observed with MnTBAP treatment. This increased production, seen under conditions of increased superoxide dismutase activity, suggests that NMDA-induced peroxynitrite production may be increased in P19 neurons. Such increased peroxynitrite production would increase tyrosine nitration, lipid peroxidation, and poly(ADPribose) polymerase activation (Szabo, 2003), processes implicated in neuronal death. In addition, glutathione peroxidase and $\mathrm{O}_{2}{ }^{\cdot}$ dismutase activities markedly decrease during the first 3 weeks of postnatal rodent life (Khan and Black, 2003), suggesting that decreased defenses against reactive nitrogen and oxygen intermediates may also play a role in the increased susceptibility of P19 neurons to NO. Consequently, glutathione depletion or NOinduced alterations of other critical cellular components may result in the developmentally regulated increase in sensitivity to $\mathrm{NO}$ toxicity that occurs during postnatal maturation.

\section{References}

Aarts M, Liu Y, Liu L, Besshoh S, Arundine M, Gurd JW, Wang YT, Salter MW, Tymianski M (2002) Treatment of ischemic brain damage by perturbing NMDA receptor-PSD-95 protein interactions. Science 298:846-850.

Almeida A, Bolanos JP, Medina JM (1999) Nitric oxide mediates glutamateinduced mitochondrial depolarization in rat cortical neurons. Brain Res 816:580-586.

Ankarcrona M, Dypbukt JM, Bonfoco E, Zhivotovsky B, Orrenius S, Lipton SA, Nicotera P (1995) Glutamate-induced neuronal death: a succession of necrosis or apoptosis depending on mitochondrial function. Neuron 15:961-973.

Antunes F, Boveris A, Cadenas E (2004) On the mechanism and biology of cytochrome oxidase inhibition by nitric oxide. Proc Natl Acad Sci USA 101:16774-16779.

Babbedge RC, Bland-Ward PA, Hart SL, Moore PK (1993) Inhibition of rat cerebellar nitric oxide synthase by 7-nitro indazole and related substituted indazoles. Br J Pharmacol 110:225-228.

Baron KT, Thayer SA (1997) CGP37157 modulates mitochondrial $\mathrm{Ca}^{2+}$ homeostasis in cultured rat dorsal root ganglion neurons. Eur J Pharmacol 340:295-300.

Baron KT, Wang GJ, Padua RA, Campbell C, Thayer SA (2003) NMDAevoked consumption and recovery of mitochondrially targeted aequorin suggests increased $\mathrm{Ca}^{2+}$ uptake by a subset of mitochondria in hippocampal neurons. Brain Res 993:124-132.

Beal MF (1992) Mechanisms of excitotoxicity in neurologic diseases. FASEB J 6:3338-3344.

Bindokas VP, Jordan J, Lee CC, Miller RJ (1996) Superoxide production in rat hippocampal neurons: selective imaging with hydroethidine. J Neurosci $16: 1324-1336$.

Boveris A, Valdez LB, Alvarez S, Zaobornyj T, Boveris AD, Navarro A (2003) Kidney mitochondrial nitric oxide synthase. Antioxid Redox Signal 5:265-271.

Bringold U, Ghafourifar P, Richter C (2000) Peroxynitrite formed by mitochondrial NO synthase promotes mitochondrial $\mathrm{Ca}^{2+}$ release. Free Radic Biol Med 29:343-348.

Brocard JB, Tassetto M, Reynolds IJ (2001) Quantitative evaluation of mitochondrial calcium content in rat cortical neurones following a glutamate stimulus. J Physiol (Lond) 531:793-805.

Brorson JR, Schumacker PT, Zhang H (1999) Nitric oxide acutely inhibits neuronal energy production. J Neurosci 19:147-158.

Brown GC (1999) Nitric oxide and mitochondrial respiration. Biochim Biophys Acta 1411:351-369.

Brown GC (2001) Regulation of mitochondrial respiration by nitric oxide inhibition of cytochrome c oxidase. Biochim Biophys Acta 1504:46-57.

Brown GC, Cooper CE (1994) Nanomolar concentrations of nitric oxide reversibly inhibit synaptosomal respiration by competing with oxygen at cytochrome oxidase. FEBS Lett 356:295-298.

Brustovetsky N, Dubinsky JM (2000) Limitations of cyclosporin A inhibition of the permeability transition in CNS mitochondria. J Neurosci 20:8229-8237.

Budd SL, Nicholls DG (1996) Mitochondria, calcium regulation, and acute glutamate excitotoxicity in cultured cerebellar granule cells. J Neurochem 67:2282-2291.

Buerk DG, Nair P (1993) $\mathrm{PtiO}_{2}$ and $\mathrm{CMRO}_{2}$ changes in cortex and hippocampus of aging gerbil brain. J Appl Physiol 74:1723-1728.

Castilho RF, Ward MW, Nicholls DG (1999) Oxidative stress, mitochondrial function, and acute glutamate excitotoxicity in cultured cerebellar granule cells. J Neurochem 72:1394-1401.

Choi DW, Rothman SM (1990) The role of glutamate neurotoxicity in hypoxic-ischemic neuronal death. Annu Rev Neurosci 13:171-182.

Colbourne F, Sutherland GR, Auer RN (1999) Electron microscopic evidence against apoptosis as the mechanism of neuronal death in global ischemia. J Neurosci 19:4200-4210.

Dawson V, Kizushi V, Huang P, Snyder S, Dawson T (1996) Resistance to neurotoxicity in cortical cultures from neuronal nitric oxide synthasedeficient mice. J Neurosci 16:2479-2487.

Dawson VL, Dawson TM, London ED, Bredt DS, Snyder SH (1991) Nitric oxide mediates glutamate neurotoxicity in primary cortical cultures. Proc Natl Acad Sci USA 88:6368-6371.

Dedkova EN, Ji X, Lipsius SL, Blatter LA (2003) Mitochondrial calcium uptake stimulates nitric oxide production in mitochondria of bovine vascular endothelial cells. Am J Physiol Cell Physiol 286:C406-C415.

Dessi F, Ben-Ari Y, Charriaut-Marlangue C (1995) Ruthenium red protects against glutamate-induced neuronal death in cerebellar culture. Neurosci Lett 201:53-56.

Elfering SL, Sarkela TM, Giulivi C (2002) Biochemistry of mitochondrial nitric-oxide synthase. J Biol Chem 277:38079-38086.

Feng ZC, Roberts Jr EL, Sick TJ, Rosenthal M (1988) Depth profile of local oxygen tension and blood flow in rat cerebral cortex, white matter and hippocampus. Brain Res 445:280-288.

Fennell JP, Brosnan MJ, Frater AJ, Hamilton CA, Alexander MY, Nicklin SA, 
Heistad DD, Baker AH, Dominiczak AF (2002) Adenovirus-mediated overexpression of extracellular superoxide dismutase improves endothelial dysfunction in a rat model of hypertension. Gene Ther 9:110-117.

Filippin L, Magalhaes PJ, Di Benedetto G, Colella M, Pozzan T (2003) Stable interactions between mitochondria and endoplasmic reticulum allow rapid accumulation of calcium in a subpopulation of mitochondria. J Biol Chem 278:39224-39234.

Frandsen A, Schousboe A (1990) Development of excitatory amino acid induced cytotoxicity in cultured neurons. Int J Dev Neurosci 8:209-216.

Ghafourifar P, Richter C (1997) Nitric oxide synthase activity in mitochondria. FEBS Lett 418:291-296.

Giulivi C (2003) Characterization and function of mitochondrial nitricoxide synthase. Free Radic Biol Med 34:397-408.

Giulivi C, Poderoso JJ, Boveris A (1998) Production of nitric oxide by mitochondria. J Biol Chem 273:11038-11043.

Gwag BJ, Koh JY, DeMaro JA, Ying HS, Jacquin M, Choi DW (1997) Slowly triggered excitotoxicity occurs by necrosis in cortical cultures. Neuroscience 77:393-401.

Hayakawa Y, Nemoto T, Iino M, Kasai H (2005) Rapid $\mathrm{Ca}^{2+}$-dependent increase in oxygen consumption by mitochondria in single mammalian central neurons. Cell Calcium 37:359-370.

Huang ZH, Huang PL, Panahian N, Dalkara T, Fishman MC, Moskowitz MA (1994) Effects of cerebral ischemia in mice deficient in neuronal nitric oxide synthase. Science 265:1883-1885.

Huie RE, Padmaja S (1993) The reaction of NO with superoxide. Free Radic Res Commun 18:195-199.

Ischiropoulos H, Gow A (2005) Pathophysiological functions of nitric oxide-mediated protein modifications. Toxicology 208:299-303.

Itoh Y, Ma FH, Hoshi H, Oka M, Noda K, Ukai Y, Kojima H, Nagano T, Toda N (2000) Determination and bioimaging method for nitric oxide in biological specimens by diaminofluorescein fluorometry. Anal Biochem 287:203-209.

Kanai AJ, Pearce LL, Clemens PR, Birder LA, VanBibber MM, Choi S-Y, de Groat WC, Peterson J (2001) Identification of a neuronal nitric oxide synthase in isolated cardiac mitochondria using electrochemical detection. Proc Natl Acad Sci USA 98:14126-14131.

Keelan J, Vergun O, Duchen MR (1999) Excitotoxic mitochondrial depolarisation requires both calcium and nitric oxide in rat hippocampal neurons. J Physiol (Lond) 520:797-813.

Keilhoff G, Erdo SL (1991) Parallel development of excitotoxic vulnerability to $\mathrm{N}$-methyl-D-aspartate and kainate in dispersed cultures of the rat cerebral cortex. Neuroscience 43:35-40.

Khan JY, Black SM (2003) Developmental changes in murine brain antioxidant enzymes. Pediatr Res 54:77-82.

Kobayashi T, Kuroda S, Tada M, Houkin K, Iwasaki Y, Abe H (2003) Calcium-induced mitochondrial swelling and cytochrome $\mathrm{c}$ release in the brain: its biochemical characteristics and implication in ischemic neuronal injury. Brain Res 960:62-70.

Koivisto A, Matthias A, Bronnikov G, Nedergaard J (1997) Kinetics of the inhibition of mitochondrial respiration by NO. FEBS Lett 417:75-80.

Kojima H, Urano Y, Kikuchi K, Higuchi T, Hirata Y, Nagano T (1999) Fluorescent indicators for imaging nitric oxide production. Angew Chem Int Ed Engl 38:3209-3212.

Kojima H, Hirata M, Kudo Y, Kikuchi K, Nagano T (2001) Visualization of oxygen-concentration-dependent production of nitric oxide in rat hippocampal slices during aglycemia. J Neurochem 76:1404-1410.

Lacza Z, Puskar M, Figueroa JP, Zhang J, Rajapakse N, Busija DW (2001) Mitochondrial nitric oxide synthase is constitutively active and is functionally upregulated in hypoxia. Free Radic Biol Med 31:1609-1615.

Lacza Z, Horn TF, Snipes JA, Zhang J, Roychowdhury S, Horvath EM, Figueroa JP, Kollai M, Szabo C, Busija DW (2004) Lack of mitochondrial nitric oxide production in the mouse brain. J Neurochem 90:942-951.

Lafon-Cazal M, Pietri S, Culcasi M, Bockaert J (1993) NMDA-dependent superoxide production and neurotoxicity. Nature 364:535-537.

Lang-Rollin ICJ, Rideout HJ, Noticewala M, Stefanis L (2003) Mechanisms of caspase-independent neuronal death: energy depletion and free radical generation. J Neurosci 23:11015-11025.

Liu Z, Stafstrom CE, Sarkisian M, Tandon P, Yang Y, Hori A, Holmes GL (1996) Age-dependent effects of glutamate toxicity in the hippocampus. Brain Res Dev Brain Res 97:178-184.

Luetjens CM, Bui NT, Sengpiel B, Munstermann G, Poppe M, Krohn AJ, Bauerbach E, Krieglstein J, Prehn JH (2000) Delayed mitochondrial dys- function in excitotoxic neuron death: cytochrome $c$ release and a secondary increase in superoxide production. J Neurosci 20:5715-5723.

Maciel EN, Vercesi AE, Castilho RF (2001) Oxidative stress in $\mathrm{Ca}^{2+}$ induced membrane permeability transition in brain mitochondria. J Neurochem 79:1237-1245.

Marks JD, Friedman JE, Haddad GG (1996) Vulnerability of CA1 neurons to glutamate is developmentally regulated. Brain Res Dev Brain Res 97:194-206.

Marks JD, Bindokas VP, Zhang XM (2000) Maturation of vulnerability to excitotoxicity: intracellular mechanisms in cultured postnatal hippocampal neurons. Brain Res Dev Brain Res 124:101-116.

Matlib MA, Zhou Z, Knight S, Ahmed S, Choi KM, Krause-Bauer J, Phillips R, Altschuld R, Sperelakis N, Bers DM (1998) Oxygen-bridged dinuclear ruthenium amine complex specifically inhibits $\mathrm{Ca}^{2+}$ uptake into mitochondria in vitro and in situ in single cardiac myocytes. J Biol Chem 273:10223-10231.

Mattiasson G, Shamloo M, Gido G, Mathi K, Tomasevic G, Yi S, Warden CH, Castilho RF, Melcher T, Gonzalez-Zulueta M, Nikolich K, Wieloch T (2003) Uncoupling protein-2 prevents neuronal death and diminishes brain dysfunction after stroke and brain trauma. Nat Med 9:1062-1068.

Mattson MP, Wang H, Michaelis EK (1991) Developmental expression, compartmentalization, and possible role in excitotoxicity of a putative NMDA receptor protein in cultured hippocampal neurons. Brain Res 565:94-108.

Mayer B, Klatt P, Bohme E, Schmidt K (1992) Regulation of neuronal nitric oxide and cyclic GMP formation by $\mathrm{Ca}^{2+}$. J Neurochem 59:2024-2029.

Montero M, Alonso MT, Carnicero E, Cuchillo-Ibanez I, Albillos A, Garcia AG, Garcia-Sancho J, Alvarez J (2000) Chromaffin-cell stimulation triggers fast millimolar mitochondrial $\mathrm{Ca}^{2+}$ transients that modulate secretion. Nat Cell Biol 2:57-61.

Monyer H, Burnashev N, Laurie DJ, Sakmann B, Seeburg PH (1994) Developmental and regional expression in the rat brain and functional properties of four NMDA receptors. Neuron 12:529-540.

Nicholls DG, Budd SL (2000) Mitochondria and neuronal survival. Physiol Rev 80:316-360.

Niquet J, Baldwin RA, Allen SG, Fujikawa DG, Wasterlain CG (2003) Hypoxic neuronal necrosis: protein synthesis-independent activation of a cell death program. Proc Natl Acad Sci USA 100:2825-2830.

Pivovarova NB, Nguyen HV, Winters CA, Brantner CA, Smith CL, Andrews SB (2004) Excitotoxic calcium overload in a subpopulation of mitochondria triggers delayed death in hippocampal neurons. J Neurosci 24:5611-5622.

Rakhit RD, Mojet MH, Marber MS, Duchen MR (2001) Mitochondria as targets for nitric oxide-induced protection during simulated ischemia and reoxygenation in isolated neonatal cardiomyocytes. Circulation 103:2617-2623.

Riobo NA, Melani M, Sanjuan N, Fiszman ML, Gravielle MC, Carreras MC, Cadenas E, Poderoso JJ (2002) The modulation of mitochondrial nitricoxide synthase activity in rat brain development. J Biol Chem 277:42447-42455.

Riva MA, Tascedda F, Molteni R, Racagni G (1994) Regulation of NMDA receptor subunit mRNA expression in the rat brain during postnatal development. Brain Res Mol Brain Res 25:209-216.

Rothman SM (1984) Synaptic release of excitatory amino acid neurotransmitter mediates anoxic neuronal death. J Neurosci 4:1884-1891.

Sattler R, Charlton MP, Hafner M, Tymianski M (1998) Distinct influx pathways, not calcium load, determine neuronal vulnerability to calcium neurotoxicity. J Neurochem 71:2349-2364.

Sattler R, Xiong Z, Lu WY, Hafner M, MacDonald JF, Tymianski M (1999) Specific coupling of NMDA receptor activation to nitric oxide neurotoxicity by PSD-95 protein. Science 284:1845-1848.

Schulz J, Matthews R, Jenkins B, Ferrante R, Siwek D, Henshaw D, Cipolloni P, Mecocci P, Kowall N, Rosen B, Beal FM (1995) Blockade of neuronal nitric oxide synthase protects against excitotoxicity in vivo. J Neurosci 15:8419-8429.

Sengpiel B, Preis E, Krieglstein J, Prehn JH (1998) NMDA-induced superoxide production and neurotoxicity in cultured rat hippocampal neurons: role of mitochondria. J Neurosci 10:1903-1910.

Sinor JD, Boeckman FA, Aizenman E (1997) Intrinsic redox properties of $\mathrm{N}$-methyl-D-aspartate receptor can determine the developmental expression of excitotoxicity in rat cortical neurons in vitro. Brain Res 747:297-303.

Stout AK, Reynolds IJ (1999) High-affinity calcium indicators underesti- 
mate increases in intracellular calcium concentrations associated with excitotoxic glutamate stimulations. Neuroscience 89:91-100.

Stout AK, Raphael HM, Kanterewicz BI, Klann E, Reynolds IJ (1998) Glutamate-induced neuron death requires mitochondrial calcium uptake. Nat Neurosci 1:366-373.

Szabo C (2003) Multiple pathways of peroxynitrite cytotoxicity. Toxicol Lett 140-141:105-112.

Ushmorov A, Ratter F, Lehmann V, Droge W, Schirrmacher V, Umansky V (1999) Nitric oxide-induced apoptosis in human leukemic lines requires mitochondrial lipid degradation and cytochrome $\mathrm{c}$ release. Blood 93:2342-2352.

Wang GJ, Thayer SA (2002) NMDA-induced calcium loads recycle across the mitochondrial inner membrane of hippocampal neurons in culture. J Neurophysiol 87:740-749.

Wang H, Yu S-W, Koh DW, Lew J, Coombs C, Bowers W, Federoff HJ, Poirier
GG, Dawson TM, Dawson VL (2004) Apoptosis-inducing factor substitutes for caspase executioners in NMDA-triggered excitotoxic neuronal death. J Neurosci 24:10963-10973.

Webb EC (1992) Enzyme nomenclature 1992: recommendations of the Nomenclature Committee of the International Union of Biochemistry and Molecular Biology on the nomenclature and classification of enzymes. San Diego: Academic.

White RJ, Reynolds IJ (1997) Mitochondria accumulate $\mathrm{Ca}^{2+}$ following intense glutamate stimulation of cultured rat forebrain neurones. J Physiol (Lond) 498:31-47.

Xia Y, Ragan RE, Seah EE, Michaelis ML, Michaelis EK (1995) Developmental expression of $N$-methyl-D-aspartate (NMDA)-induced neurotoxicity, NMDA receptor function, and the NMDAR1 and glutamate- binding protein subunits in cerebellar granule cells in primary cultures. Neurochem Res 20:617-629. 